\title{
A Comparison between Gravity Wave Momentum Fluxes in Observations and Climate Models
}

\author{
Marvin A. Geller, ${ }^{*}$ M. Joan Alexander, ${ }^{+}$Peter T. Love,* Julio Bacmeister, \\ MANFred ERn,,${ }^{@}$ Albert Hertzog,,${ }^{\&}$ Elisa MAnzini,** Peter Preusse, ${ }^{@}$ \\ KAORU SATO, ${ }^{++}$ADAM A. SCAIFE, ${ }^{\# \#}$ AND TIEHAN ZHOU ${ }^{@ @}$ \\ * Stony Brook University, Stony Brook, New York \\ ${ }^{+}$NorthWest Research Associates/CoRA, Boulder, Colorado \\ \# National Center for Atmospheric Research, Boulder, Colorado \\ ${ }^{\circledR}$ Forschungszentrum Jülich GmbH, Jülich, Germany \\ \& École Polytechnique, Palaiseau, France \\ ** Max Planck Institute for Meteorology, Hamburg, Germany \\ ${ }^{++}$Department of Earth and Planetary Science, Graduate School of Science, The University of Tokyo, Tokyo, Japan \\ \#\# Met Office Hadley Centre, Exeter, United Kingdom \\ ${ }^{\circledR}$ NASA Goddard Institute for Space Studies, and Center for Climate Systems Research, \\ Columbia University, New York, New York
}

(Manuscript received 26 July 2012, in final form 27 February 2013)

\begin{abstract}
For the first time, a formal comparison is made between gravity wave momentum fluxes in models and those derived from observations. Although gravity waves occur over a wide range of spatial and temporal scales, the focus of this paper is on scales that are being parameterized in present climate models, sub-1000-km scales. Only observational methods that permit derivation of gravity wave momentum fluxes over large geographical areas are discussed, and these are from satellite temperature measurements, constant-density long-duration balloons, and high-vertical-resolution radiosonde data. The models discussed include two high-resolution models in which gravity waves are explicitly modeled, Kanto and the Community Atmosphere Model, version 5 (CAM5), and three climate models containing gravity wave parameterizations, MAECHAM5, Hadley Centre Global Environmental Model 3 (HadGEM3), and the Goddard Institute for Space Studies (GISS) model. Measurements generally show similar flux magnitudes as in models, except that the fluxes derived from satellite measurements fall off more rapidly with height. This is likely due to limitations on the observable range of wavelengths, although other factors may contribute. When one accounts for this more rapid fall off, the geographical distribution of the fluxes from observations and models compare reasonably well, except for certain features that depend on the specification of the nonorographic gravity wave source functions in the climate models. For instance, both the observed fluxes and those in the high-resolution models are very small at summer high latitudes, but this is not the case for some of the climate models. This comparison between gravity wave fluxes from climate models, high-resolution models, and fluxes derived from observations indicates that such efforts offer a promising path toward improving specifications of gravity wave sources in climate models.
\end{abstract}

\section{Introduction}

Gravity wave parameterizations are needed in atmospheric climate models in order to simulate the influence of subgrid-scale atmospheric gravity waves, which are

Corresponding author address: Marvin A. Geller, School of Marine and Atmospheric Sciences, Stony Brook University, Stony Brook, NY 11794-5000.

E-mail: marvin.geller@sunysb.edu necessary to produce realistic winds and temperatures. Gravity wave drag forces are important at levels throughout the atmosphere, including the troposphere, stratosphere, and mesosphere and above in the thermosphere and ionosphere (e.g., Fritts and Alexander 2003). There are a variety of different methods of gravity wave parameterization, but they all have many commonalities (e.g., see McLandress and Scinocca 2005).

All gravity wave parameterizations contain certain parameters that have been poorly constrained by 
observations. Such parameters have historically been chosen on the bases of being physically reasonable and giving model results that are consistent with observations. One common constraint is good agreement between the model and observations of the monthly and zonally averaged zonal winds and temperatures throughout the year. More sophisticated constraints have involved realistic modeling of the frequency of stratospheric warmings (e.g., Richter et al. 2010), obtaining a realistic quasi-biennial oscillation (QBO) (e.g., Scaife et al. 2000) and having a realistic stratospheric transport circulation (e.g., Shepherd 2007), although these latter phenomena may also depend on boundary conditions and the radiative calculations in the simulations. A key quantity is the momentum flux (also called stress or pseudomomentum flux). In parameterizations, this flux is set at a level in the lower atmosphere near the wave sources. The magnitude of the momentum flux is important in determining the wave breaking levels and hence the vertical profile of wave dissipation and the resulting force on the mean flow. Tuning parameters effectively modify this flux to obtain realistic middle atmosphere winds and temperatures in most models. (See appendix A for the basic principles of wave-mean flow interaction formulation underlying the parameterizations.)

Recently, new methods for deriving gravity wave momentum fluxes from global observations have been developed (Vincent et al. 1997; Ern et al. 2004; Alexander et al. 2008; Hertzog et al. 2008). Also, high-resolution global climate models (e.g., Watanabe et al. 2008) have been developed that seek to explicitly resolve gravity waves that are parameterized in coarser-resolution models. Since the Watanabe et al. (2008) model gives mean zonal winds, zonally averaged temperatures, and even a QBO that resemble observations (Kawatani et al. 2010), one might expect that the modeled gravity wave momentum fluxes should resemble those in the real atmosphere.

In this paper, we will compare gravity wave momentum fluxes derived from satellite, radiosonde, and constantdensity long-duration balloons to gravity wave momentum fluxes in three state-of-the-art climate models that utilize three different formulations for their gravity wave parameterizations. We also compare these to gravity wave momentum fluxes that are explicitly resolved in two high-resolution climate models. Because the application of our results will help in constraining parameterizations in global models, we focus in this work on observation methods that give wide enough geographical and temporal coverage to be termed global and can provide at least monthly-mean values to represent climatology. Although climate models respond both to explicitly resolved and parameterized gravity waves, our strategy in this paper is to compare parameterized gravity wave momentum fluxes in climate models and those from gravity waves from high-resolution models that are subgrid scale in climate models. Thus, we are focusing on only this part of the total gravity wave spectrum (i.e., waves with horizontal wavelengths typically shorter than $1000 \mathrm{~km}$ ).

The remainder of this paper is organized as follows: Section 2 describes the observations and the methods employed to estimate gravity wave momentum fluxes. Limitations associated with these observational results guide the details of our comparisons to the models. Three climate models and their gravity wave parameterization methods are described in section 3. Section 3 also describes the high-resolution models and the methods for extracting gravity wave momentum fluxes from these models. Section 4 contains the comparisons among the models and observations, and section 5 is a discussion of the results. Future observational analysis and modeling work needed to advance the subject are also presented in this section. A brief review of wavemean flow interaction theory and parameterization can be found in appendix A, and appendix B is a discussion comparing absolute gravity wave momentum fluxes, which are derived from satellite observations, and net gravity wave momentum fluxes, which are what appear in the model equations.

\section{Gravity wave momentum flux observations}

Atmospheric gravity waves are observed using many different methods, but only relatively few can be used to estimate momentum flux. Furthermore, of the latter, only a few give wide enough geographic and temporal coverage to be termed "global." Because we will be comparing observations to climate models, which cannot realistically represent local weather or finescale regional climate, our comparisons are limited to observations with global-scale coverage and good representation of monthly-mean momentum fluxes. Thus, for example, while radars give valuable information on gravity wave momentum fluxes, such measurements are available at only a few locations and often for only limited periods. In our comparisons, we include five observational datasets that have global-scale coverage and sufficient time sampling to represent monthly-mean values. These include three analyses of satellite observations, results from long-duration superpressure balloons, and results from radiosondes. A review of these methods for estimating momentum fluxes appears in Alexander et al. (2010), including the assumptions, equations, and limitations associated with each method. Here we only briefly describe the observations and 
methods for computing momentum fluxes and present comparisons of the zonal-mean momentum fluxes.

\section{a. Satellite methods}

Satellite methods rely on high-resolution temperature measurements to define the horizontal and vertical structure of the waves, which allows an estimate of wave momentum flux. Frequency information is unavailable from twice-daily observations from high-inclination satellites, so the medium-frequency approximation to the linear dispersion and polarization relations is used: that is, $f \ll \hat{\omega} \ll N$, where $f$ is the Coriolis parameter, $\hat{\omega}$ is the gravity wave intrinsic frequency, and $N$ is the Brunt-Väisälä frequency (for more details, see Fritts and Alexander 2003). Under these assumptions, the magnitude of the vector momentum flux $|M|$ is proportional to the square of the temperature amplitude $T$ times the ratio of horizontal $\mathbf{k}$ to vertical $m$ wavenumber, or $T^{2} \times|\mathbf{k}| / m$, and the direction of the vector flux is in the direction of wave propagation $\mathbf{k} /|\mathbf{k}|$. The satellite data included in this paper are from highresolution limb-sounding instruments: High Resolution Dynamics Limb Sounder (HIRDLS; described in Gille et al. 2008) and Sounding of the Atmosphere using Broadband Emission Radiometry (SABER; described by Russell et al. 1999). In these data, $\mathbf{k}$ is the most uncertain component of the momentum fluxes because the high horizontal resolution occurs in only one direction, along the measurement track. This means that the estimated horizontal wavenumber is an "apparent wavenumber" $k_{a}$ in the plane of the measurement track, which will not generally coincide with the plane of wave propagation. Therefore, generally $k_{a}<|\mathbf{k}|$, and the estimated momentum flux is generally smaller than the true flux. This uncertainty, together with sparse alongtrack sampling, results in a low bias error in the momentum fluxes derived from the satellite data (e.g., Preusse et al. 2009b), and this error is likely to be large, possibly by a factor of 2 (Ern et al. 2004). The satellite methods also provide no directional information about the wave propagation or vector momentum flux. Despite these limitations, these methods have the unique advantages of nearly global coverage and long duration: $3 \mathrm{yr}$ for HIRDLS and $10 \mathrm{yr}$ for SABER. The minimum horizontal wavelength that can be resolved with these limb sounders is twice the horizontal sampling rate: $\sim 2 \times 100 \mathrm{~km}$ for HIRDLS and $\sim 2 \times 200 \mathrm{~km}$ for SABER. Minimum resolved vertical wavelengths are $\sim 3 \mathrm{~km}$ for HIRDLS and $\sim 4.5 \mathrm{~km}$ for SABER. Because of the proportionality of the flux to $|\mathbf{k}| / m$, the minimum horizontal wavelength and the maximum vertical wavelength will have limiting effects on the magnitude of the momentum flux derived from these satellite observations.
Taken together, the limitations on satellite methods mean the derived momentum fluxes can be considered a reasonable lower-limit estimate.

\section{1) HIRDLS MOMENTUM FLUXES}

The HIRDLS instrument on the Aura satellite provided three full years of observations (2005-08) between latitudes $64^{\circ} \mathrm{S}$ and $80^{\circ} \mathrm{N}$. Gille et al. (2008) provide a complete description of the instrument and measurements. Version 6 data are used in our analyses. HIRDLS temperature profiles have vertical resolution of $\sim 1 \mathrm{~km}$ and along-track horizontal spacing between adjacent profiles of $\sim 100 \mathrm{~km}$.

A spectral analysis (e.g., wavelet decomposition) in the vertical gives temperature amplitude as a function of vertical wavenumber and altitude $T(m, z)$; then the shift in phase for matching waves in adjacent profiles gives $k_{a}$. Two different methods for estimating gravity wave momentum fluxes from HIRDLS data are included in this paper. The primary difference between them is the method for matching waves in adjacent profiles.

The first method (HIRDLS1) follows Alexander et al. (2008). This method finds the maximum amplitude signal that appears in both profiles through a cospectral analysis of adjacent temperature profiles. This method retains all of the data, even when this covarying signal may be small. The second method (HIRDLS2) follows Ern et al. (2011). This method finds the largest signal in each profile. It then only retains profile pairs when this largest signal has the approximately the same vertical wavelength in each member of the pair. This method discards about half the data when this matching criterion fails.

Our analysis indicates this difference in data retention is the leading cause of differences in the momentum flux estimates from the two methods. Apparently, quite often, when the HIRDLS2 method discards a profile pair, the covarying signal that HIRDLS1 retains has a relatively small momentum flux.

Another difference in the two methods is in the way the "background" temperature is calculated. The background temperature is subtracted from the raw temperature profiles to define the temperature perturbations prior to the spectral analysis. This is a secondary cause of differences between the two results. There are also other small differences in the analysis methods that are expected to have some effects at the lowest $(20 \mathrm{~km})$ and highest $(50 \mathrm{~km})$ altitudes. At $20 \mathrm{~km}$, the results may be particularly sensitive to the treatment of high clouds in the tropics and to the spectral method used. Both HIRDLS1 and HIRDLS2 methods exclude data where clouds are detected. Clouds can contaminate the data at tropical latitudes where deep convection and high cirrus 

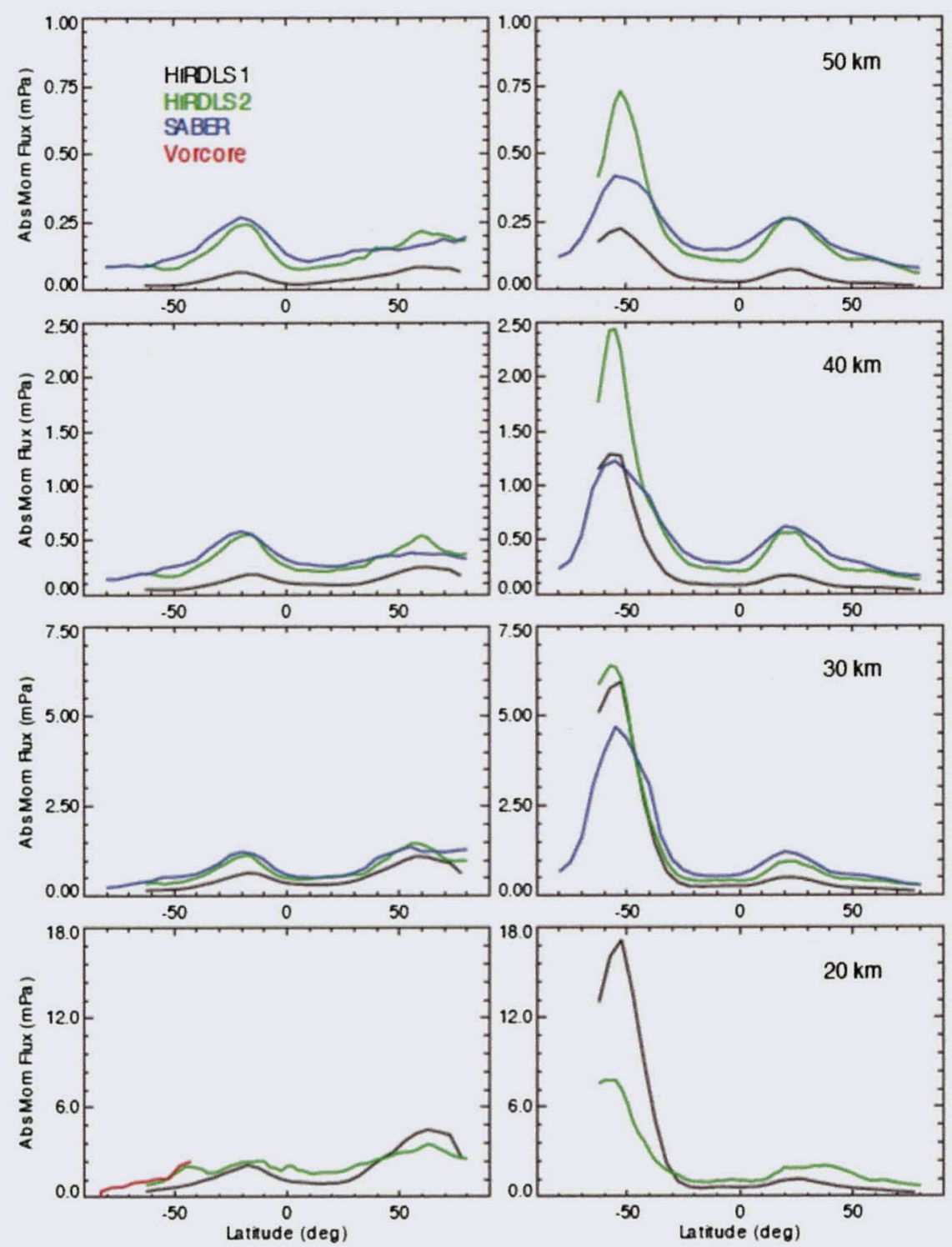

FIG. 1. Comparison of absolute gravity wave momentum fluxes at altitudes of 20, 30, 40 , and $50 \mathrm{~km}$ derived from two different methods using HIRDLS data, one method using SABER data, and Vorcore data for (left) January and (right) July 2006. Note that the January Vorcore data are only available at $20-\mathrm{km}$ altitude, and SABER data is only available at altitudes $\geq 30 \mathrm{~km}$.

occur near the tropopause. Polar stratospheric clouds may also be important at polar winter latitudes. Last, the spectral window width, which is fixed for HIRDLS2 but varies with vertical wavelength for HIRDLS1, may cause errors at different latitudes in the wave retrievals near the upper and lower boundaries of the data coverage.

Zonal-mean absolute momentum fluxes versus latitude derived from the two methods HIRDLS1 and HIRDLS2 are shown in Fig. 1 with black and green lines, respectively. The left column shows January 2006, and the right column shows July 2006. The two HIRDLS methods show very similar seasonal patterns. They also show very similar interannual variability (shown later). The largest fluxes occur at Southern Hemisphere winter latitudes, maximizing just south of $50^{\circ} \mathrm{S}$. Note that these are the latitudes where the HIRDLS measurement track turns toward an east-west orientation and where stratospheric zonal winds are at a maximum. Here, the zonal sampling is optimal for observing short horizontal wavelength waves propagating in the zonal direction, including mountain waves, and many waves 
are expected to occur in the winter jet region. In the north, this turn-around latitude occurs near $80^{\circ} \mathrm{N}$. Thus, some of the contrast between northern and southern winter fluxes, where southern fluxes are approximately three times larger, may be due, in part, to north/south differences in sampling. Both HIRDLS1 and HIRDLS2 also exhibit a subtropical summer peaks near $20^{\circ}$ and a uniform decrease of the flux at high latitude in both seasons.

The methods display differences as well. At $20-30 \mathrm{~km}$ in northern summer latitudes, HIRDLS2 is generally higher than HIRDLS1 by about a factor of 2. HIRDLS2 would be expected to be somewhat larger because of the use of fewer measurements in the average in HIRDLS2. Peak values increase as less data are used in an average because of intermittency in wave amplitudes (Alexander 2010). HIRDLS2 may also be generally larger than HIRDLS1 away from the large-amplitude mountain wave regions because HIRDLS2 will tend to eliminate small values when vertical wavelengths do not match in adjacent profiles, while the HIRDLS1 method retains these small values. It has actually been checked that, when the HIRDLS2 method discards a profile pair, the covarying signal that HIRDLS1 retains often has a relatively small momentum flux. An interesting fact nonetheless is that profiles eliminated with the HIRDLS2 method had similar temperature variance as profiles that were retained. This suggests the possibility that the waves eliminated from the HIRDLS2 analysis because of mismatched vertical wavelengths might have similar momentum fluxes as the waves in the retained profiles if they were better resolved.

Results from the two analysis methods also differ in their height variations (shown more clearly later in this paper). These differences could be related to differences in the fractional number of profile pairs retained in HIRDLS1 and HIRDLS2 means, and could also be related to the HIRDLS1 and HIRDLS2 fluxes being more similar at $30 \mathrm{~km}$ than at $20 \mathrm{~km}$, where the differences in the treatments of clouds and the lower boundary should be smaller.

The HIRDLS1 and HIRDLS2 differences shown in Fig. 1 indicate how different methods of analysis affect the derived average absolute gravity wave momentum fluxes, since these two analyses start with the same HIRDLS dataset. Our analysis indicates that the difference in data retention is the leading cause of discrepancy in the momentum flux estimates from the two methods. Given known gravity wave intermittencies, it is actually important to understand the representativeness of different methods of analysis on these derived average momentum fluxes. Thus, we make the recommendation that future reporting of gravity wave momentum fluxes clearly states how these averages were computed and what fraction of the available data was used in constructing these averages. Concerning HIRDLS2 and HIRDLS1, a further study into how these two different methods of analysis influence derived absolute fluxes and which method is more representative of the actual average momentum fluxes is clearly needed but is beyond the scope of this paper.

\section{2) SABER MOMENTUM FLUXES}

Data from the SABER instrument on the TIMED satellite includes temperature profiles with $\sim 2-\mathrm{km}$ vertical resolution at altitudes from the tropopause to $100 \mathrm{~km}$. The satellite has a 60-day yaw cycle, which gives continuous measurements at latitudes $50^{\circ} \mathrm{S}-50^{\circ} \mathrm{N}$ but alternates every 60 days with measurements continuing poleward to either $50^{\circ}-82^{\circ} \mathrm{N}$ or $50^{\circ}-82^{\circ} \mathrm{S}$. The momentum flux analysis is identical to the HIRDLS2 method described above (Ern et al. 2011). Horizontal spacing between profiles is $\sim 200 \mathrm{~km}$. One notable change in the analysis since the Ern et al. (2011) description is the treatment of tides, which is primarily important at mesospheric altitudes.

Noise in the SABER temperatures is much larger in the lower stratosphere, so results are only shown at $30 \mathrm{~km}$ and above in Fig. 1. SABER momentum fluxes (blue line) show very similar variations with latitude to what is seen in both the HIRDLS results. Comparing SABER to HIRDLS2, which were analyzed with identical methods, it is interesting to see that SABER is either similar to or larger than HIRDLS2 at all altitudes in January, an apparently paradoxical result since the HIRDLS data have better resolution in both the horizontal and vertical and should therefore always be resolving a larger portion of the wave spectrum. At winter high latitudes in July, south of $50^{\circ} \mathrm{S}$, HIRDLS2 is always larger than SABER, and these differences are likely showing the effect of the optimal HIRDLS sampling there.

Like both HIRDLS methods, SABER shows momentum fluxes uniformly decreasing poleward of $60^{\circ}$, which is an important contrast with some of the model results that will be shown in section 3 .

\section{b. VORCORE superpressure balloon measurements}

Superpressure balloons drift with the wind and observe horizontal wind and pressure anomalies associated with waves (Hertzog and Vial 2001). The correlations between these variables are used to compute vector momentum fluxes (Vincent et al. 2007; Boccara et al. 2008). The worst uncertainties of the satellite measurements associated with the uncertain propagation directions of waves are therefore eliminated in the 
superpressure balloon measurements. Measurements from the Vorcore campaign (Hertzog et al. 2008) represent waves observed at a single point in space, but they are limited to 15 -min time resolution by data rate limitations. Spatial sampling is also limited by the Lagrangian trajectories of balloons launched from McMurdo Station in Antarctica to only give results at one altitude, approximately $20 \mathrm{~km}$. The fluxes derived from the Vorcore balloons are considered the most accurate global-scale measurements available, for waves with intrinsic frequencies $\hat{\omega}$ lower than $2 \pi(1 \mathrm{~h})^{-1}$. Because intrinsic frequencies are measured, the fluxes include a low-frequency correction factor equal to $1-\left(f^{2} / \hat{\omega}^{2}\right)$ (Sato et al. 1997). Vorcore measurements span September 2005-January 2006.

Zonal-mean values of the absolute Vorcore fluxes from January 2006 are shown in the bottom-left panel of Fig. 1 as the red line. The fluxes are uniformly larger by a factor of 2-3 over those from HIRDLS1, as may be expected because of the known low bias in satellite methods, yet agree better with HIRDLS2. Vorcore fluxes show the same uniform decrease toward the pole seen in the satellite results.

\section{c. Radiosonde momentum fluxes}

Radiosonde observations use the quadrature spectrum of horizontal wind and temperature anomalies to estimate vector momentum fluxes (Vincent et al. 1997). High-resolution radiosondes from U.S. stations have been analyzed with these methods to estimate momentum flux. The observations and method of analysis are known to only include low intrinsic frequency waves $\sim(1-10) f$. We will focus here on the North American region, where there is a high density of sounding sites. Previous studies have shown the mean intrinsic frequencies and horizontal wavelengths observed with radiosondes over North America are $\sim(2.5-3.5) f$ and $300-700 \mathrm{~km}$, respectively (Wang et al. 2005).

A comparison of gravity wave momentum fluxes derived from U.S. high-vertical-resolution radiosonde data at $\sim 20 \mathrm{~km}$ with those derived from satellite observations and models will be shown in section 4 .

\section{Models}

Five models are discussed in this section. The Hadley Centre Global Environmental Model 3 (HadGEM3), MAECHAM5, and the Goddard Institute for Space Studies (GISS) model are atmospheric general circulation models encompassing the middle atmosphere and constructed to be used in long climate simulations. These three models are characterized by relatively coarse horizontal and vertical grids and large dissipations at short spatial scales ("conventional resolution"), not resolving scales smaller than $\sim 1000 \mathrm{~km}$. These three models utilize parameterizations to account for gravity wave momentum fluxes and their deposition arising through unresolved waves at smaller scales. The Kanto model is a high-resolution model that obtains a realistic middle atmosphere without any parameterized gravity waves, and a fifth model [Community Atmosphere Model, version 5 (CAM5)] is a conventional climate model that is simply run at high horizontal resolution.

Each of these is briefly discussed below. Figure 2 is analogous to Fig. 1 but shows momentum fluxes from these five models instead of observations. All the models were run with specified, observed surface temperatures for 2005-07 but are generally very similar to the atmospheric model components used in phase 5 of the Coupled Model Intercomparison Project (CMIP5; Taylor et al. 2012).

\section{a. Parameterized gravity waves in conventional- resolution climate models}

The three climate models shown in Fig. 2 are HadGEM3, MAECHAM5, and GISS with horizontal resolutions ranging from $1.25^{\circ}$ to $2.5^{\circ}$. These three models all use different methodologies for parameterizing both orographic and nonorographic gravity waves. Details about each model configuration and the parameterizations are described below. To compare to the observed momentum fluxes, the model momentum fluxes plotted in Fig. 2 are the sum of the absolute value of all gravity wave momentum fluxes at a given altitude, regardless of direction. For the three climate models (HadGEM3, MAECHAM5, and GISS), the orographic plus nonorographic parameterized gravity wave fluxes are plotted. For the Kanto model and CAM5, the sub$1000-\mathrm{km}$ wavelength gravity wave fluxes resolved in these models are plotted. (See appendixes A and B for some discussion on the physics foundation for gravity wave parameterizations and the difference between net momentum flux and this absolute momentum flux.)

\section{1) HADGEM3}

The version of the Met Office Unified Model (UM) that is used in these comparisons has been described in Walters et al. (2011). This version has a horizontal grid resolution of $1.25^{\circ}$ (latitude) by $1.875^{\circ}$ (longitude). Its top level is at $84 \mathrm{~km}$, and there are 85 vertical levels. The formulation of Webster et al. (2003) is used for the orographic gravity wave parameterization. The nonorographic gravity wave parameterization is based on the ultrasimple spectral parameterization (USSP) given by Warner and McIntyre (2001) and implemented as in Scaife et al. (2002). The wave source for the nonorographic gravity wave parameterization is 

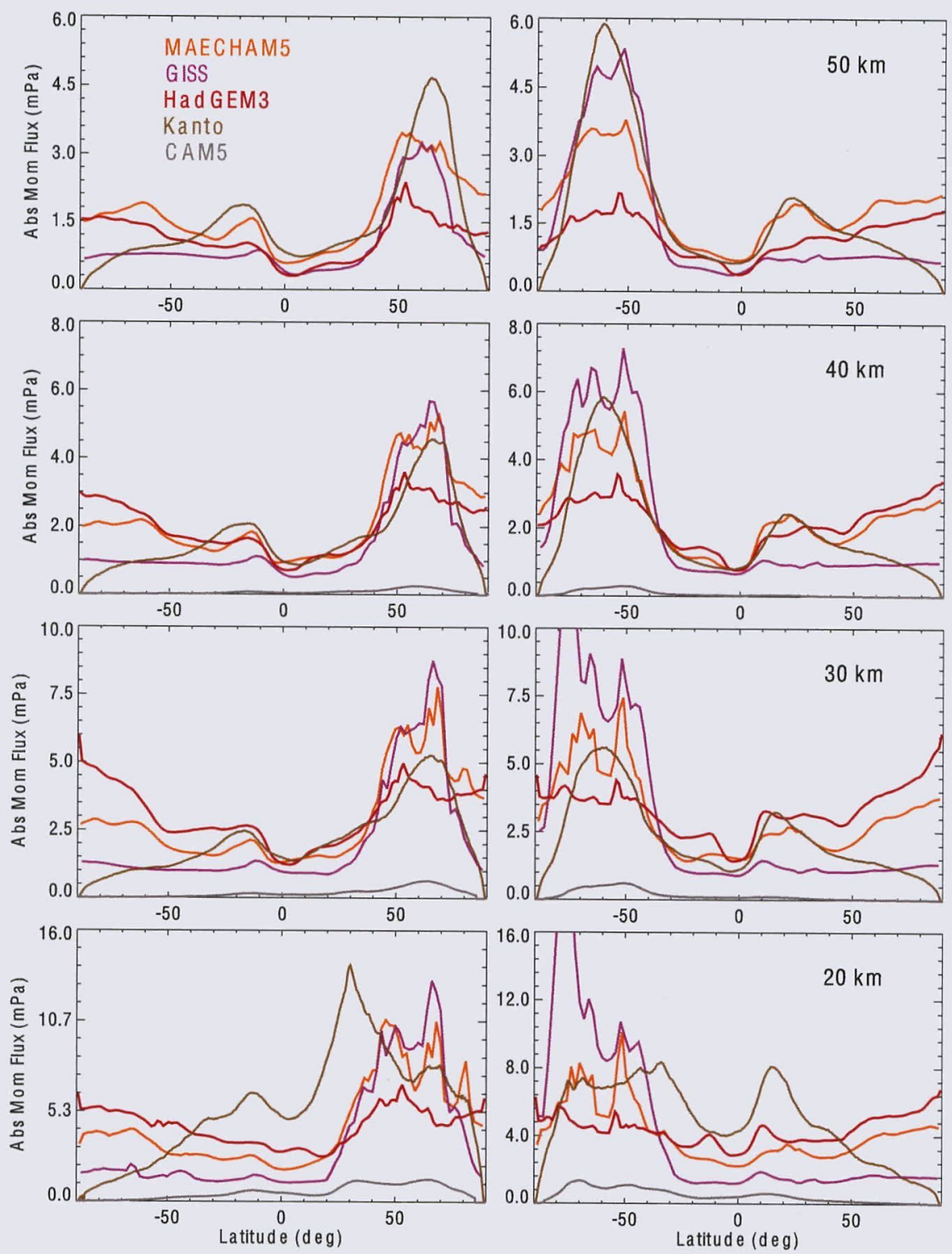

FIG. 2. Comparison of the absolute gravity wave momentum fluxes from the HadGEM3, the MAECHAM5 model, a version of the GISS model, the Kanto model, and the CAM5 at altitudes of 20,30, 40, and $50 \mathrm{~km}$ for (left) January and (right) July 2006.

taken to be globally uniform at the launch level, which is set to model level 11 near the top of the boundary layer with a total momentum flux of $9.9 \mathrm{mPa}$. It is taken to be isotropic, with one-fourth this amount in each of the four vector directions (eastward, westward, northward, and southward). The source momentum flux spectrum peaks at a $4.3-\mathrm{km}$ vertical wavelength. The HadGEM3 produces rather realistic mean zonal winds and temperatures, although the Southern Hemisphere (SH) winter winds show insufficient equatorward tilt in the upper stratosphere. A realistic QBO with period and amplitude similar to observations is produced in this model (Scaife et al. 2000).

\section{2) MAECHAM5}

The MAECHAM5 model is the middle atmosphere configuration of the ECHAM5 model, and a brief description of this model is given in Manzini et al. (2006). It is a spectral model, and the results shown here are with T63 spectral resolution, which corresponds to a spatial resolution of $1.875^{\circ}$ (lat.) by $1.875^{\circ}$ (lon.) and has 95 layers in the vertical, with 44 of these levels being between 100 and $1 \mathrm{hPa}$ so that the vertical layers in this region have thicknesses of approximately $770 \mathrm{~m}$. The model top is at $0.01 \mathrm{hPa}$. The Lott and Miller (1997) parameterization is used for the orographic gravity 
waves, and the Hines (1997) scheme is used for the parameterization of nonorographic gravity waves. The source level for the nonorographic Hines (1997) scheme is at approximately $700 \mathrm{hPa}$, and the source function is taken to be isotropic in eight directions and globally uniform with a gravity wave rms wind speed of $1 \mathrm{~m} \mathrm{~s}^{-1}$ and an effective horizontal wavenumber $K^{*}=2 \pi /$ $(126 \mathrm{~km})$. The MAECHAM5 is also able to produce quite a realistic $\mathrm{QBO}$, as has been described by Giorgetta et al. (2006). Similar deficiencies are seen in the SH winter winds below about $1 \mathrm{hPa}$ as are seen in the HadGEM3.

\section{3) GISS}

The version of the NASA Goddard Institute for Space Studies climate model used here is derived from the GISS Model $\mathrm{E}$ that has been described and compared to observations in Schmidt et al. (2006). It is a gridpoint model with $2^{\circ}$ (latitude) by $2.5^{\circ}$ (longitude) horizontal resolution. It has 40 layers, with its top at $0.1 \mathrm{hPa}$, and the vertical thickness of its stratospheric layers range from 1.1 to about $4 \mathrm{~km}$, so with this resolution it does not give a realistic self-generated $\mathrm{QBO}$. The version of the GISS model used here has been described by Geller et al. (2011). It uses the McFarlane (1987) parameterization for orographic gravity waves, while the Alexander and Dunkerton (1999) parameterization is used for nonorographic gravity waves. The source spectrum is applied at an altitude of $100 \mathrm{hPa}$ and is specified to have the $B_{2}$ spectral shape (see, e.g., Gong et al. 2008). The nonorographic source momentum flux is taken to be isotropic, and it is taken to be zonally symmetric but variable with latitude and time as given in Fig. 7 of Geller et al. (2011). The nonorographic gravity wave momentum flux varies with respect to latitude and time to notionally simulate the gravity wave sources by deep convection in the tropics and by jet emission at high latitudes. For reference, the tropical nonorographic vertical momentum flux $\rho_{0} \overrightarrow{u^{\prime} w^{\prime}}$ has a maximum of $1.5 \mathrm{mPa}$, whereas the maximum high-latitude Northern Hemisphere winter jet emission source is about $1.5 \mathrm{mPa}$ and the maximum high-latitude Southern Hemisphere winter jet emission is around $5.0 \mathrm{mPa}$. The GISS results shown in Geller et al. (2011) showed realistic winds below about $1 \mathrm{hPa}$. Although this version of the GISS model does not have a modeled $\mathrm{QBO}$, this is present in a more recent version of the model with enhanced tropical gravity wave fluxes and finer vertical resolution.

\section{b. Resolved gravity waves in high-resolution climate models}

Two high-resolution climate models with a spectrum of resolved gravity waves are described in this section, and details of the model configurations are given below.
Exact computation of the momentum flux in the resolved gravity wave spectrum would require saving model output at time intervals that are only a fraction of the shortest period wave $(<5 \mathrm{~min})$ and would require spectral analysis of the component winds with computation of the covariance of vertical and horizontal wind components. Computation of momentum flux from simple multiplication of the vertical and horizontal wind components $\left(u^{\prime} w^{\prime}\right.$ and $\left.v^{\prime} w^{\prime}\right)$ can lead to gross underestimation of the total fluxes because of cancellation of waves propagating in opposite directions. To avoid these errors, we have devised and tested an approximation using wind and temperature quadratics $\left(u^{\prime 2}, v^{\prime 2}, w^{\prime 2}\right.$, and $T^{\prime 2}$ ). The total absolute gravity wave momentum fluxes are estimated as

$$
\begin{aligned}
& \begin{aligned}
\mathbf{M}^{2} & =\left(1-\frac{f^{2}}{\hat{\omega}^{2}}\right) \rho_{0}^{2}\left[\left(\overline{u^{\prime} w^{\prime}}\right)^{2}+\left(\overline{v^{\prime} w^{\prime}}\right)^{2}\right] \\
& =\rho_{0}^{2} w^{\prime 2}\left(u^{\prime 2}+v^{\prime 2}\right)\left[1-\frac{f^{2}}{\hat{\omega}^{2}}\right]\left[1+\frac{f^{2}}{\hat{\omega}^{2}}\right]^{-1},
\end{aligned} \\
& \text { where } \frac{f^{2}}{\hat{\omega}^{2}}=\left(\frac{f g}{w^{\prime} N^{2}}\right)^{2}\left(\frac{T^{\prime}}{T_{0}}\right)^{2} .
\end{aligned}
$$

The quantities $T_{0}$ and $\rho_{0}$ are the large-scale temperature and density, respectively. The primes denote deviations from this large scale, which is chosen here to be $1000 \mathrm{~km}$. The right-hand side of Eq. (1) is derived using the gravity wave polarization and dispersion relations. The terms in square brackets represents the low-frequency corrections to the flux. At low frequencies, a monochromatic wave has a nonzero wind component perpendicular to the wave propagation direction (with an amplitude equal to $f / \hat{\omega}$ times that of the parallel wind component) that does not contribute to the momentum flux. Hence, if the wave were propagating purely zonally, the meridional wind component $v^{\prime 2}=u^{\prime 2}(f / \hat{\omega})^{2}$ and accounting for this component requires dividing by $\left[1+(f / \hat{\omega})^{2}\right]$. Since intrinsic frequency is not known, it can be approximated from the vertical wind and temperature anomalies as shown in Eq. (1). This lowfrequency correction is appreciable but less than $25 \%$ for gravity waves resolved in Kanto and CAM5. The square root of Eq. (1) is plotted in Fig. 2 for Kanto and CAM5.

\section{1) KANTO MODEL}

The Kanto model (see Watanabe et al. 2008) was specially developed, based on a Center for Climate System Research (CCSR)/National Institute for Environmental Studies (NIES)/Frontier Research Center for 
Global Change (FRCGC) general circulation model, to resolve much of the gravity wave spectrum explicitly and to run without any gravity wave parameterizations. To obtain realistic mean winds and temperatures with only those gravity waves that are resolved, the Kanto model runs with very little dissipation at small scales (see Fig. 6 in Watanabe et al. 2008). The Kanto model has both very fine horizontal resolution (T213) corresponding to a latitude-longitude grid of $0.5625^{\circ}$, or $62.5 \mathrm{~km}$ near the equator, and a vertical resolution of $300 \mathrm{~m}$ throughout the stratosphere and mesosphere (256 layers) with its model top at $85 \mathrm{~km}$. The model time step was $30 \mathrm{~s}$. All gravity waves are spontaneously generated in the Kanto model and propagate three dimensionally, governed by inherent wave dynamics (Sato et al. 2009).

The Kanto model produces realistic winds and temperatures and self-generates a QBO but with too short a period (about 15 months). It produces June-August (JJA) winter westerlies of the correct magnitude, and they show the equatorward slope seen in observations. The December-February (DJF) winter westerlies are a little too strong, and the jet core lacks the equatorward tilt that is seen in the 40-yr European Centre for Medium-Range Weather Forecasts (ECMWF) ReAnalysis (ERA-40). It is interesting to note that, even though gravity waves with horizontal wavelengths less than about $250 \mathrm{~km}$ are underrepresented in the Kanto model, the generated QBO still has too short a period. It is thought that this might be due to too weak tropical upwelling in the Kanto model (see Kawatani et al. 2010).

\section{2) CAM5}

CAM5 is a state-of-the-art, low-top climate model with an upper boundary around $2 \mathrm{hPa}$ (Neale et al. 2010). It employs a Lindzen-type parameterization of orographic gravity wave drag (Lindzen 1981; McFarlane 1987). CAM5 does not include any parameterization of nonorographic gravity wave effects. Complete documentation of CAM5 is provided in Neale et al. (2010).

In this study we use the finite-volume (FV) dynamical core ( $\operatorname{Lin} 2004$ ) with a horizontal resolution of $0.23^{\circ}$ latitude by $0.31^{\circ}$ longitude and 30 layers in the vertical. A physics time step of $15 \mathrm{~min}$ is used. In its top three layers (above about $25 \mathrm{~km}$,) the order of CAM's advection operators drops from third to first and very coarse vertical resolution is employed. Also, explicit second-order damping of momentum fields is applied in this region. We examine results from two 18-month experiments forced by observed sea surface temperatures (SST) initialized on 1 June 2005 from different atmospheric initial conditions.

We do not show the zonal wind and temperature climatologies of these models in this paper, since they appear in papers by the respective modeling groups (e.g., Giorgetta et al. 2006; Scaife et al. 2002; Geller et al. 2011; Watanabe et al. 2008). Although CAM5 mean zonal wind results have not yet been published, CAM5 mean zonal winds show a similar pattern to the National Centers for Environmental Prediction (NCEP) reanalyses and differ by less than about $5 \mathrm{~m} \mathrm{~s}^{-1}$ below $10 \mathrm{hPa}$ or $30 \mathrm{~km}$ (A. Gettelman 2012, personal communication).

\section{c. Model comparison}

Looking at Fig. 2, at $20 \mathrm{~km}$, for January 2006, there is a great deal of similarity in the momentum fluxes from all the models, except that the CAM5 fluxes are much smaller. In January, there is a maximum at high northern latitudes from all models, although the Kanto fluxes peak at a lower latitude than the others. The magnitudes at this maximum do differ by about a factor of 2 , with the GISS and Kanto fluxes being slightly larger than the MAECHAM5 fluxes and the HadGEM3 fluxes being significantly smaller. The Kanto, GISS, and CAM5 fluxes decrease toward zero at latitudes near the North Pole, while only the Kanto and CAM5 fluxes decrease toward zero near the South Pole in January. This feature undoubtedly results from the nonorographic gravity wave source specifications in the models with parameterizations. The Kanto fluxes are similar to the parameterized fluxes, while the CAM5 fluxes are much smaller at all altitudes. A summer subtropical secondary maximum is seen in the Kanto fluxes and also CAM5, although weakly, but not seen in the others. The January fluxes at the higher altitudes are again quite similar in shape, with a high latitude maximum and a much smaller summer, subtropical secondary maximum.

All the July fluxes from the models have a similar shape, with maxima at high latitudes and a much smaller summer, subtropical secondary maximum. The maximum winter hemisphere fluxes vary by up to a factor of 4. Comparing the scales of Fig. 1 and 2, it is apparent that the fluxes derived from observations are much smaller in January at all levels, while in July the fluxes are of similar size at 20 and $30 \mathrm{~km}$ but much smaller at 40 and $50 \mathrm{~km}$.

\section{Comparisons of gravity wave fluxes in observations and models}

Before showing comparisons between gravity wave momentum fluxes in models and those observed, we should first discuss the differences between the momentum fluxes important in models and the momentum flux information derived from the various observations. In the model momentum equations the convergence of parameterized gravity wave momentum fluxes is an 

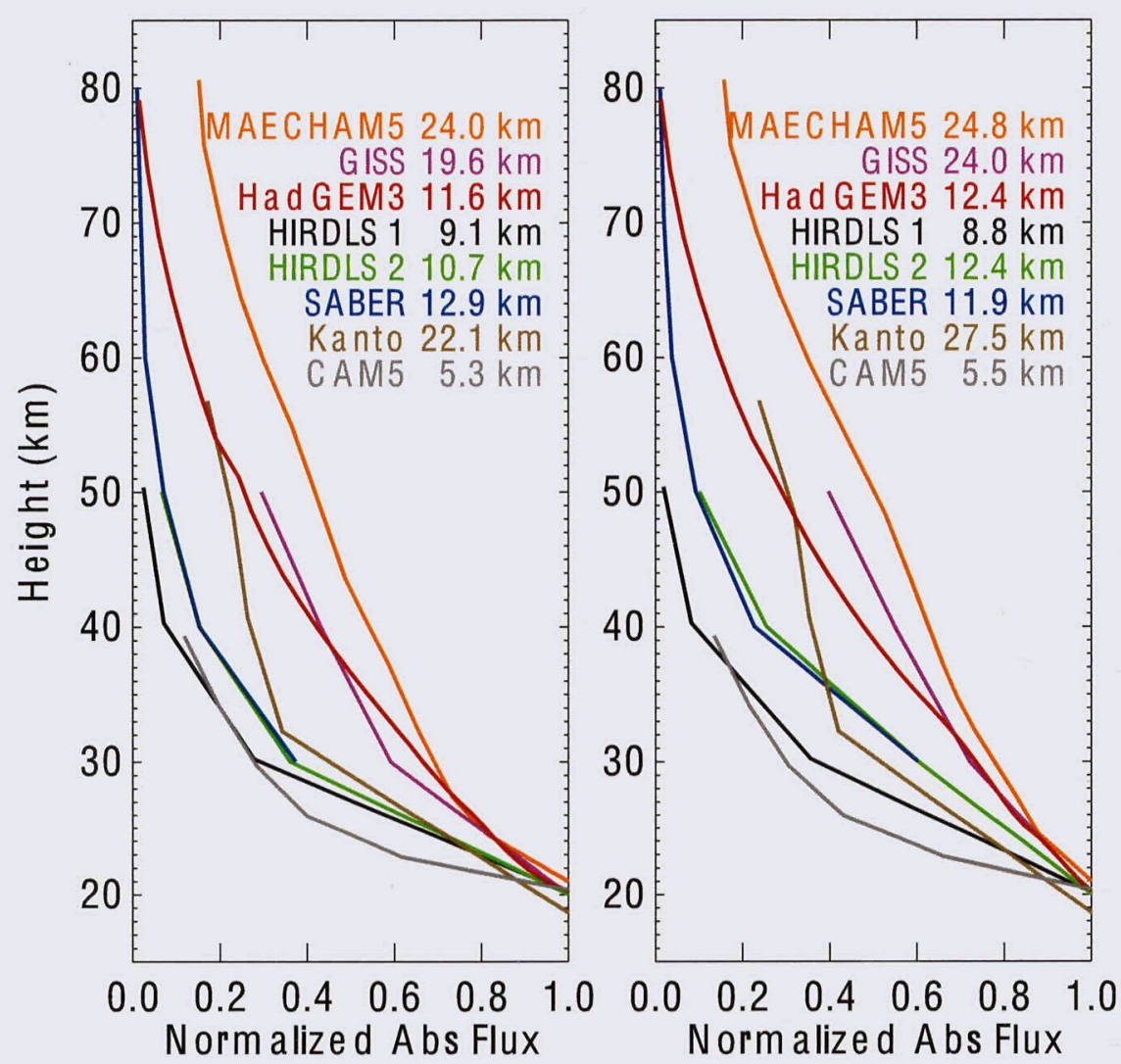

FIG. 3. Comparisons between the globally averaged absolute gravity wave momentum fluxes for the MAECHAM5, HadGEM3, and GISS models with gravity wave parameterizations; the Kanto and CAM5 high-resolution models without nonorographic gravity wave parameterizations; and two different methods for deriving gravity momentum fluxes derived from HIRDLS data, as well as derived from SABER data: (left) January and (right) July 2006.

important term determining the time dependence of the winds. On the other hand, while east-west and northsouth gravity wave momentum fluxes can be derived from high-resolution radiosonde data and from longduration constant-density balloons, only the absolute gravity wave momentum fluxes can be derived from satellite radiance information. Mathematically speaking, the vector components $\rho_{0} \overline{u^{\prime} w^{\prime}}$ and $\rho_{0} \overline{v^{\prime} w^{\prime}}$ from the gravity wave parameterizations in conventional models are what are important. The high-resolution models, on the other hand, seek to explicitly resolve much of the gravity wave spectrum (although the CAM5 does have orographic gravity wave parameterizations). For the Kanto and CAM5 models, we seek to compare with that portion of the wave spectrum that is parameterized in climate models, as explained in section $3 b$.

Another point to be emphasized here is that all methods of observing gravity wave fluctuations are subject to their own unique "observational window." This is emphasized in Alexander et al. (2010), where the details of observational windows from several techniques are shown in Fig. 7 of that paper.

\section{a. Global GW momentum fluxes}

Figure 3 shows the globally averaged gravity wave absolute momentum fluxes from all the models, along with the satellite-derived momentum fluxes, for January and July 2006. They are normalized to be the same at $20 \mathrm{~km}$. The scale heights for each of these fluxes are also given; that is to say, the rate of exponential decay is determined for several altitude intervals and the averaged scale height for the momentum fluxes are shown in this figure. We see that the models with gravity wave parameterizations all seem to fall off with altitude similarly. The fact that the HadGEM3 scale height is smaller than those from the other two climate models and Kanto by a factor of 2, agreeing better with the satellite scale heights, is due to the fact that its fluxes fall off much more rapidly with height at lower altitudes, and the averaging emphasizes this. The satellite-derived 
fluxes fall off much more rapidly with altitude than do those from the models with gravity wave parameterizations. The Kanto model lies in between the models with parameterizations and the satellite-derived values. The scale height for Kanto is due to its slower fall off at high altitudes. The CAM5 fluxes fall off the most rapidly in both January and July.

Figure 4 shows maps for the gravity wave momentum fluxes for January 2006 at $40 \mathrm{~km}$, while Fig. 5 shows the same for July 2006. In each contour plot, the gridded absolute momentum flux data have been divided by the global-mean value at that height, which is given in each plot title (and plotted in Fig. 3). For example, the absolute momentum flux at the tip of the Antarctic Peninsula in the July SABER data is $2.0 \mathrm{mPa}$, which is the contour level $10^{0.6}$ multiplied by the global-mean absolute momentum flux $0.5 \mathrm{mPa}$. Remarkably, we see quite good agreement in spatial patterns among all the models and the satellite observations. All the maps show maxima at high northern latitudes, the influence of topographic features are prominent in the models, and many of these features are also seen in the satellite observations. Interestingly, the summer, subtropical secondary maxima are seen more prominently in the high-resolution models and in the observations but are also seen in the models with parameterizations, albeit more weakly. The summer high latitude maxima are larger in MAECHAM5 and HadGEM3 than in Kanto, GISS, and CAM5. No such summer, high-latitude maxima are seen in the observations.

Looking next at Fig. 5, the fluxes for July 2006 at $40 \mathrm{~km}$, we see maximum fluxes at high southern latitudes in all the models and observations. We also see strong orographic fluxes above the southern tip of South America and to the south over Antarctica, where there are high topographic features. There is much less contrast between the Northern and Southern Hemisphere fluxes in the MAECHAM5 and HadGEM3 models, compared to the GISS, Kanto, and CAM5 models, as well as the satellite observations. On the other hand, the GISS model shows the least flux over the summer, subtropical continents compared to the other models and observations.

\section{b. GW momentum fluxes over Antarctica}

During October 2005, there was an intense Vorcore campaign in which 27 superpressure balloons were launched, and the measurements covered a broader range of latitudes because of the variability in vortex winds in October. Figure 6 shows comparisons between the October 2005 Vorcore-derived gravity wave absolute momentum fluxes at $20 \mathrm{~km}$ and those from the Kanto, MAECHAM5, HadGEM3, and GISS models for October 2005. The CAM5 results, however, are for an average of an ensemble of three Octobers intended to represent some of the internal variability in the model.

Note that all panels show enhanced fluxes over the Antarctic Peninsula and/or southern Andes topography. The CAM5 fluxes are again seen to be the smallest, but an enhancement over the Antarctic Peninsula resembling the Vorcore peak is simulated. The Kanto, HadGEM3, and MAECHAM5 fluxes are larger than in Vorcore, with the most spatial variability seen in Vorcore and the GISS, CAM5, and MAECHAM5 models, with some similarities in the patterns. Smaller fluxes are seen over the South Pole in Vorcore and the high-resolution models (Kanto and CAM5) but not in the climate models, consistent with Fig. 2 and the specifications of the source function in the nonorographic gravity wave parameterizations.

\section{c. GW momentum fluxes over North America}

Figure 7 shows a comparison between absolute gravity wave momentum fluxes for January (left) and July (right), derived from U.S. high-vertical-resolution radiosonde data, using the methods in Vincent et al. (1997), with those from models and satellite-derived fluxes. The radiosonde fluxes were derived using profile data from $18-25 \mathrm{~km}$ and are compared to satellite and model gravity wave fluxes at $20 \mathrm{~km}$.

In January, note the enhanced fluxes over the Rocky and, to a lesser extent, the Appalachian Mountain regions in all the models and in the radiosonde data. The Rocky Mountain enhancement is less in HadGEM3. This enhancement is much less in the HIRDLS-derived fluxes. Again, the CAM5 fluxes are smaller than the others. Enhancements in the fluxes are also seen over mountainous Alaska in the models and in the radiosonde data. These enhancements are much less obvious in the satellite-derived fluxes.

The observed July fluxes show smaller enhancements in the fluxes over the Rocky Mountain region in the models than was seen in January. It is interesting to note that enhancements are also seen in the satellite-derived and radiosonde fluxes at that time. The Kanto and, to a lesser extent, CAM5 models show enhancements over the southeast United States, and some smaller enhancements are seen in the GISS and HadGEM 3 fluxes, while little of this is seen in the MAECHAM5 fluxes. These enhancements over the southeast United States are evident in the radiosonde and satellite fluxes.

\section{d. Interannual variability in $G W$ momentum fluxes}

Although we have shown model and observationally derived gravity wave absolute momentum fluxes for January and July 2006, so far in this paper this comparison 

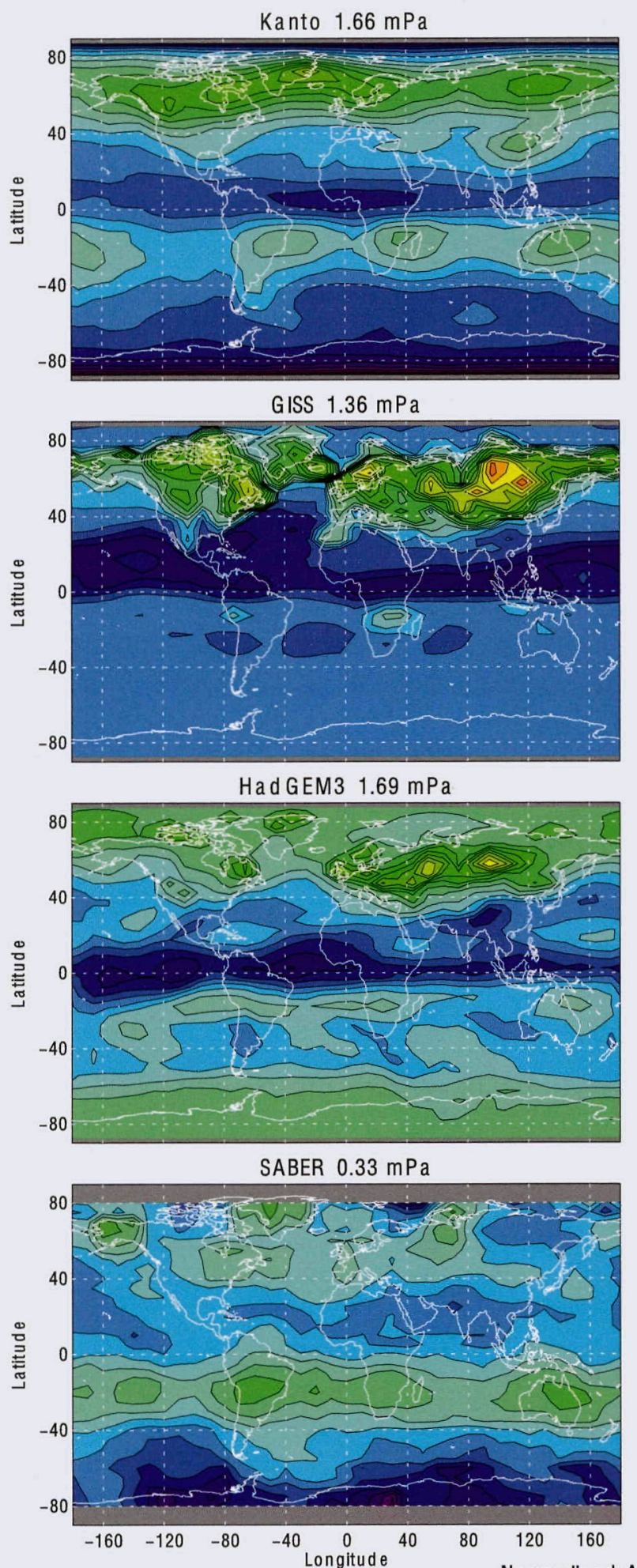

Norm alized $A$ bs Flux $\left(\log _{10}\right)$

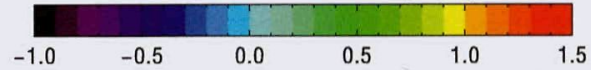

FIG. 4. Maps of model and satellite-derived absolute gravity wave momentum fluxes for January 2006 at $40 \mathrm{~km}$. The maps show log 10 of the factor multiplying the global average (shown in the title of each panel). The gray region in the Southern Hemisphere of the HIRDLS and SABER plots indicate regions where no observations were made because of orbit and viewing angle considerations. 
Kanto $1.92 \mathrm{mPa}$

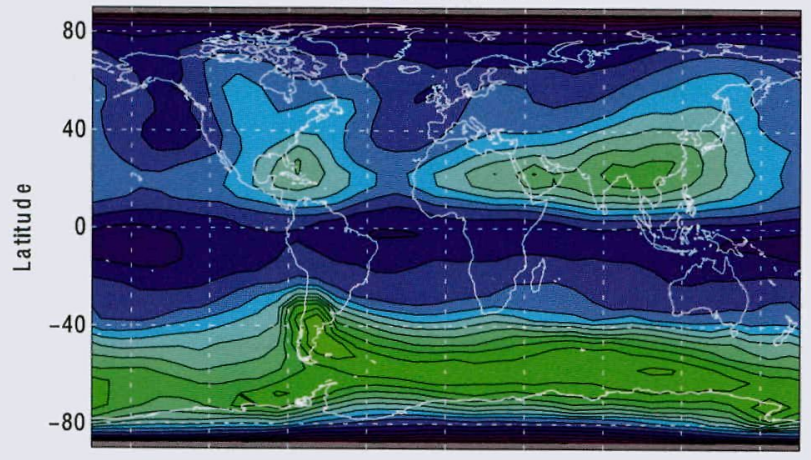

GISS $1.81 \mathrm{mPa}$

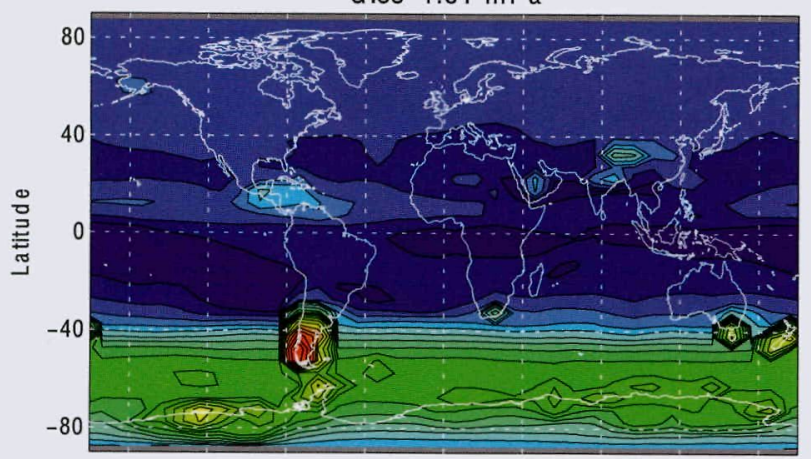

HadGEM3 $1.92 \mathrm{mPa}$

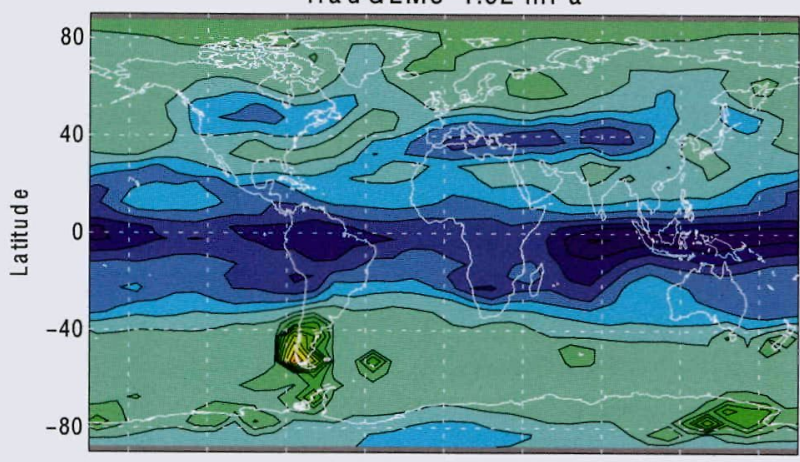

SABER $0.50 \mathrm{mPa}$

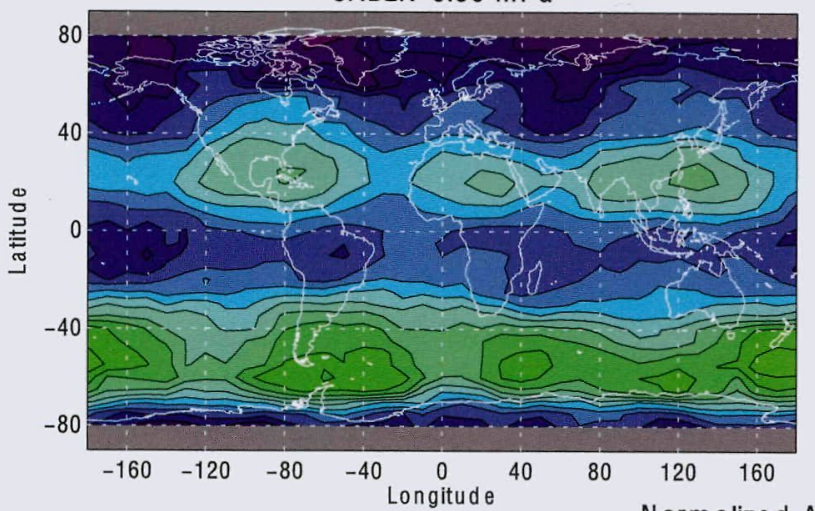

CAM5 $0.07 \mathrm{mPa}$

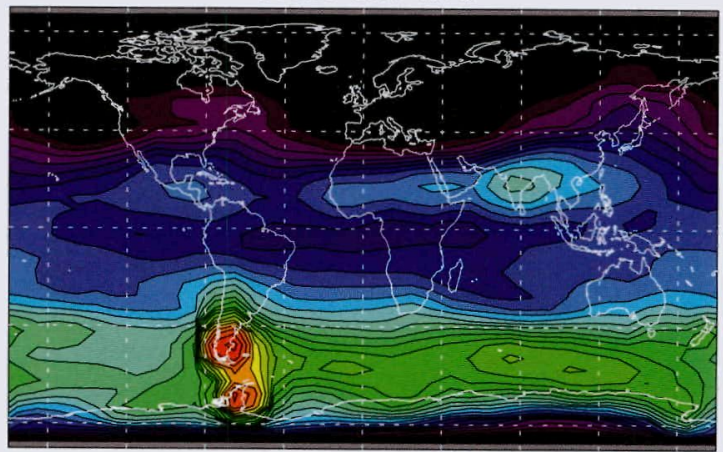

MAECHAM5 $2.10 \mathrm{mPa}$

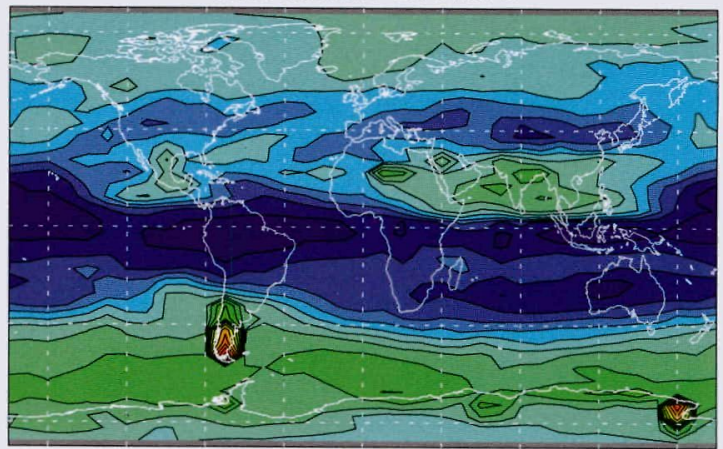

HIRDLS $10.34 \mathrm{mPa}$

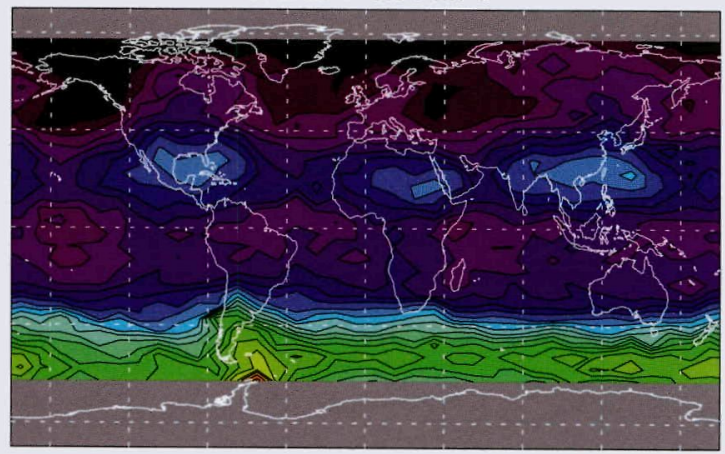

HIRDLS $20.56 \mathrm{mPa}$

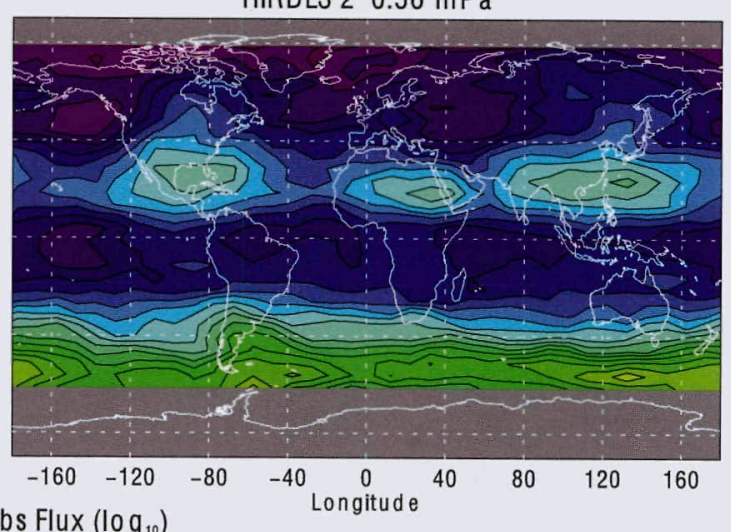

Norm alized $A$ bs Flux $\left(\log _{10}\right)$

$\begin{array}{llllll}-1.0 & -0.5 & 0.0 & 0.5 & 1.0 & 1.5\end{array}$

FIG. 5. As in Fig. 4, but for July 2006. 

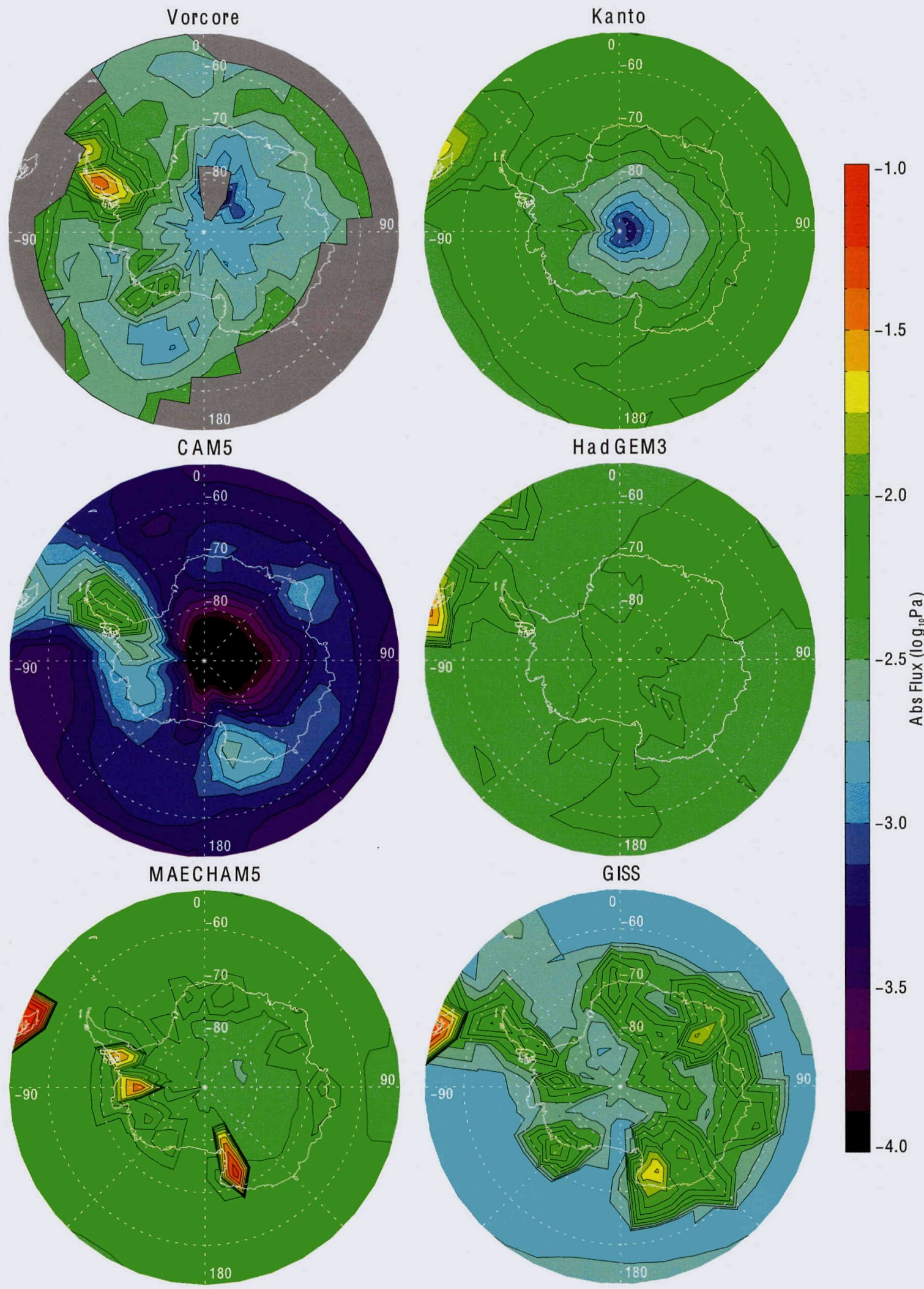

FIG. 6. Comparison between the absolute gravity wave momentum fluxes over Antarctica for October 2005 for Vorcore and the Kanto, CAM5, HadGEM3, MAECHAM5, and GISS models. All results are for an altitude of $20 \mathrm{~km}$. The CAM5 results are for an average of three October simulations. 
exercise was conducted for the years 2005, 2006, and 2007 , and, of course, there was considerable variability in the model and observationally derived fluxes. Figure 8 shows an example of the model and observed variabilities for July. Note that both observations and models indicate similar variability, with maximum variability at high winter latitudes.

\section{Discussion of results}

This paper represents the first detailed attempt to compare parameterized gravity wave momentum fluxes from climate models, resolved gravity wave momentum fluxes in high-resolution models, and gravity wave momentum fluxes derived from observations. All comparisons have been conducted using gravity wave absolute momentum fluxes; that is to say, the sum of the absolute values of the gravity wave momentum fluxes in all directions. Taking this as the basis of comparison is necessary since that is all that can be derived from satellite temperature data and satellite data are the only observational technique that gives global information. Net east-west and north-south momentum fluxes can be derived from high-resolution radiosonde data in the lower stratosphere and also from long-duration, superpressure balloons over limited latitude ranges and geographical regions, but these are not discussed in this paper.

While gravity wave absolute momentum fluxes give valuable information, the model winds are responsive to the convergences (or divergences) of the net east-west and north-south gravity wave momentum fluxes. Agreement, or lack of agreement, between absolute momentum fluxes does not imply similar agreement, or lack of same, in the gravity wave forces that the model feels. For instance, exact cancellation between eastward and westward momentum fluxes can be achieved for a variety of different absolute momentum fluxes. Nevertheless, the comparisons of absolute momentum fluxes shown here are of considerable value.

In general, in both January and July, the absolute momentum fluxes from the models agree with one another better than they do with the satellite-derived momentum fluxes. This is especially true at higher altitudes, mainly because of a much faster fall off in the satellite-derived absolute gravity wave momentum fluxes than the model fluxes. In both January and July, at $20 \mathrm{~km}$, the model and satellite-derived fluxes agree reasonably well (within a factor of about 2), but at $50 \mathrm{~km}$ the satellitederived fluxes are even smaller relative to the models. The zonally averaged absolute fluxes at $20 \mathrm{~km}$ show very similar latitudinal variations; being largest at winter high latitudes. The interannual variations in these fluxes over the three years studied are of similar size in the models and in the observations and are relatively large. Those models that produce an internally generated QBO (HadGEM3, MAECHAM5, and Kanto) have greater momentum fluxes in the deep tropics than do the models that did not have an internally generated QBO (GISS and CAM5). Finally, both the satellite-derived and highresolution models' absolute gravity wave momentum fluxes show a clear decrease toward the poles, but the models with nonorographic gravity wave parameterizations do not show this, undoubtedly because of their source flux specifications.

Geographic patterns in maps of absolute gravity wave momentum fluxes from the models and those derived from satellites agree quite well at $40 \mathrm{~km}$. While it is not surprising that the Kanto and CAM5 models, which have high resolution and explicitly are meant to resolve a large portion of the gravity wave spectrum, show larger Asian summer monsoon values, it is somewhat surprising that similar enhancements are seen in the MAECHAM5 and, to a lesser extent, in the HadGEM3 models that have globally uniform nonorographic gravity wave sources in their parameterizations, and therefore this feature must be due solely to wind filtering in those models. The HIRDLS and SABER gravity wave fluxes in July at $40 \mathrm{~km}$ clearly show enhanced gravity wave fluxes in the Asian monsoon region and over Africa and North America at the same latitudes, and these enhanced fluxes are likely mainly due to convective sources there.

Comparisons between model fluxes and Vorcore and radiosonde balloon-derived fluxes at $20 \mathrm{~km}$ are also encouraging, in that many of the absolute gravity wave momentum flux features are seen in both these observations and in the models and sometimes in the satellite fluxes. Although Kanto has similar fluxes to Vorcore away from regions of topography, the comparison shows both high-resolution models are still underresolving important orographic wave momentum fluxes.

We have displayed maps of the absolute gravity wave momentum fluxes at $40 \mathrm{~km}$, where the maps are rescaled according to the globally averaged values of these fluxes. When this is done, the maps agree quite well with one another and some valuable information emerges. For instance, the satellite data and the high-resolution models show secondary maxima in the summer subtropics and tropics, and this feature is not so obvious in models with gravity wave parameterizations. This is almost surely due to their specifications of nonorographic gravity wave momentum flux sources.

The faster fall off with height of the gravity wave momentum fluxes derived from satellite measurements than in models is the most severe disagreement between measured and model fluxes shown in this paper. Looking 

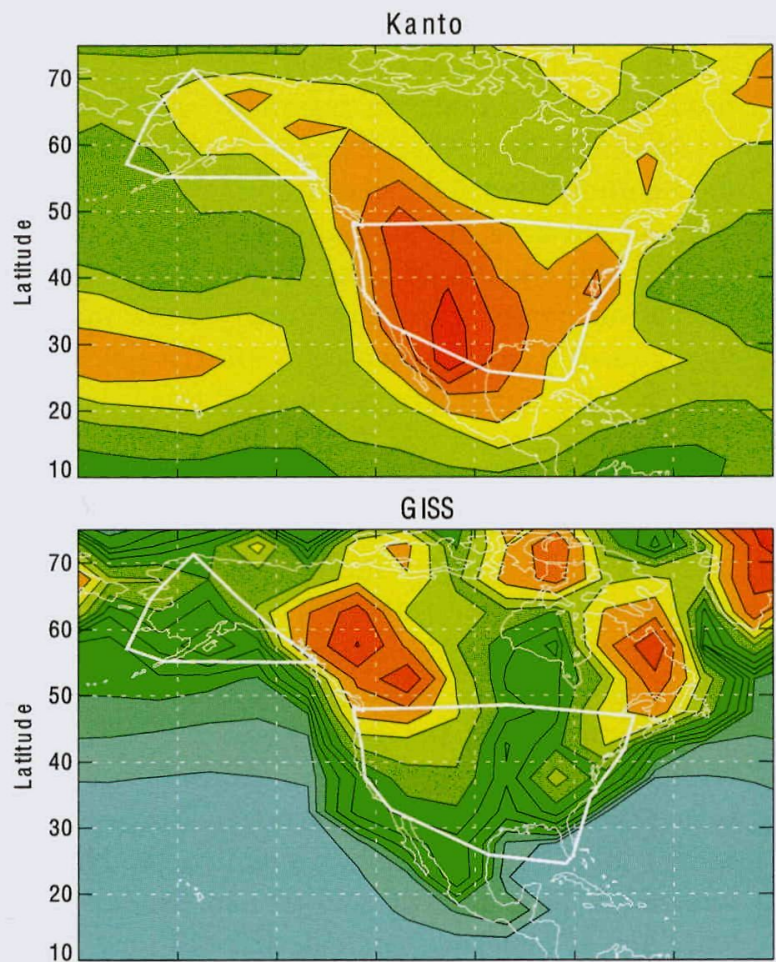

Had GEM3

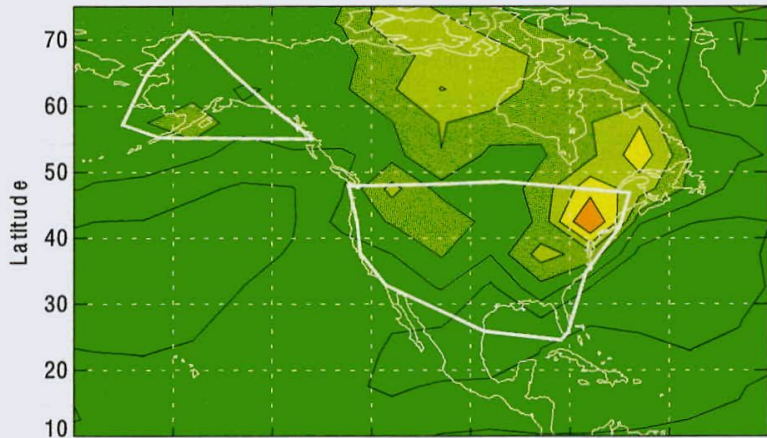

Ra diosonde

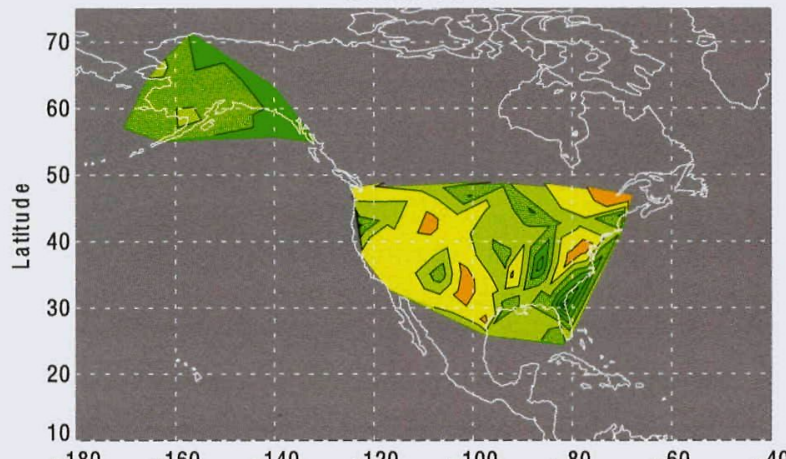

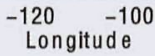

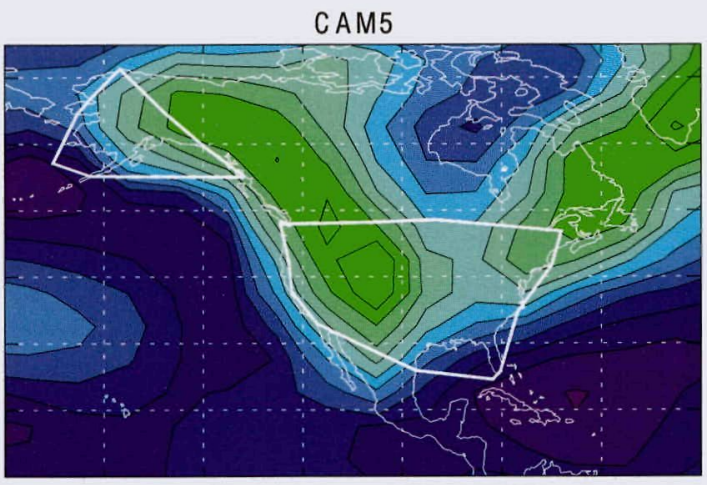

MAECHAM5

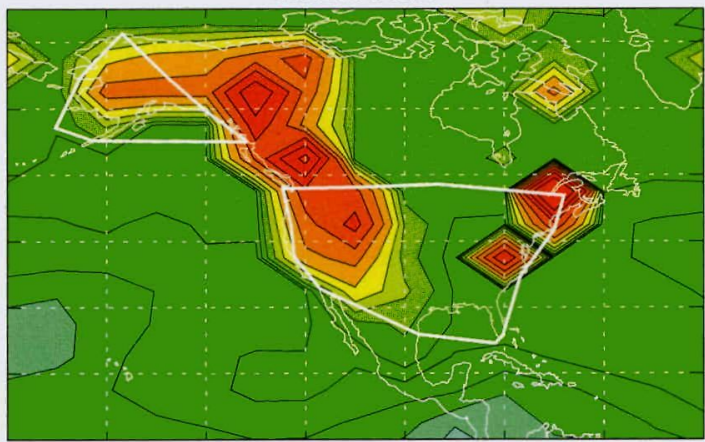

HIRDLS 1

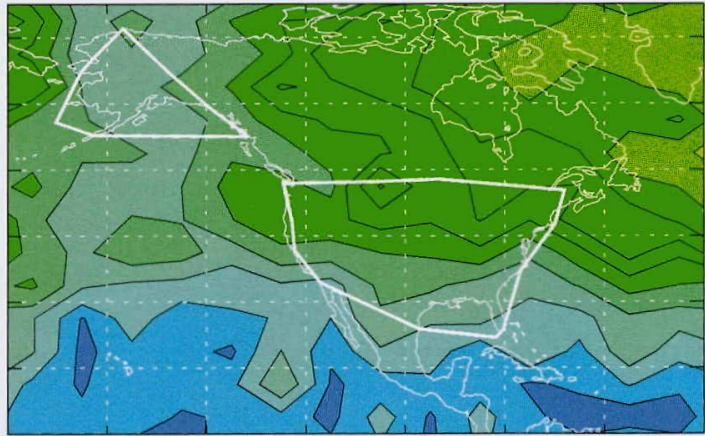

HIRDLS 2

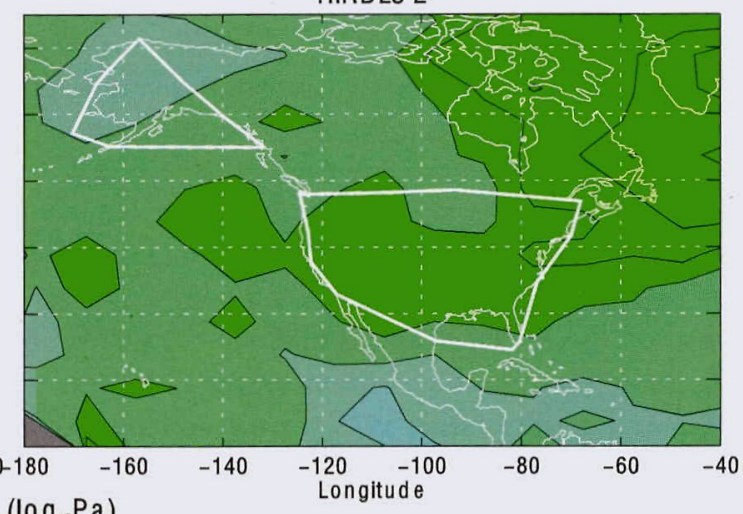

Abs Flux (log $\mathrm{Pa})$

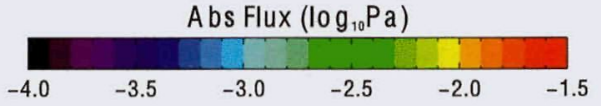

FIG. 7. (a) January comparison of gravity wave absolute momentum fluxes at $20 \mathrm{~km}$ from models from satellite and and radiosonde data.

The white outlined region indicates where U.S. high-vertical-resolution radiosonde data are available. (b) As in (a), but for July. 


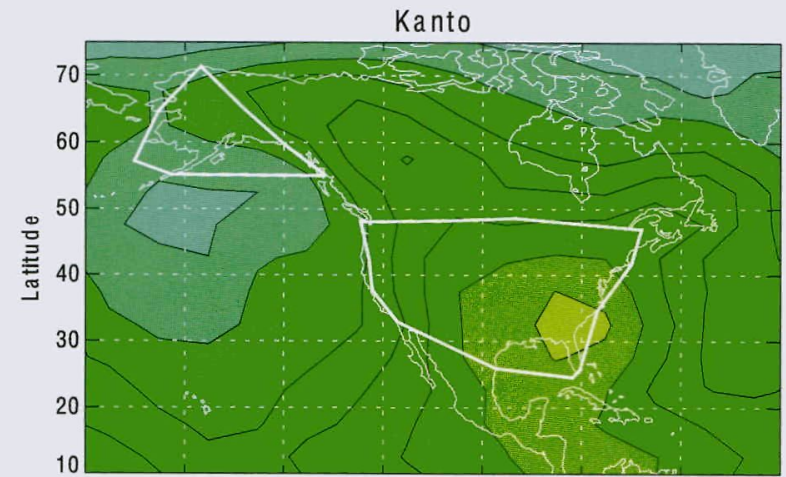

GISS
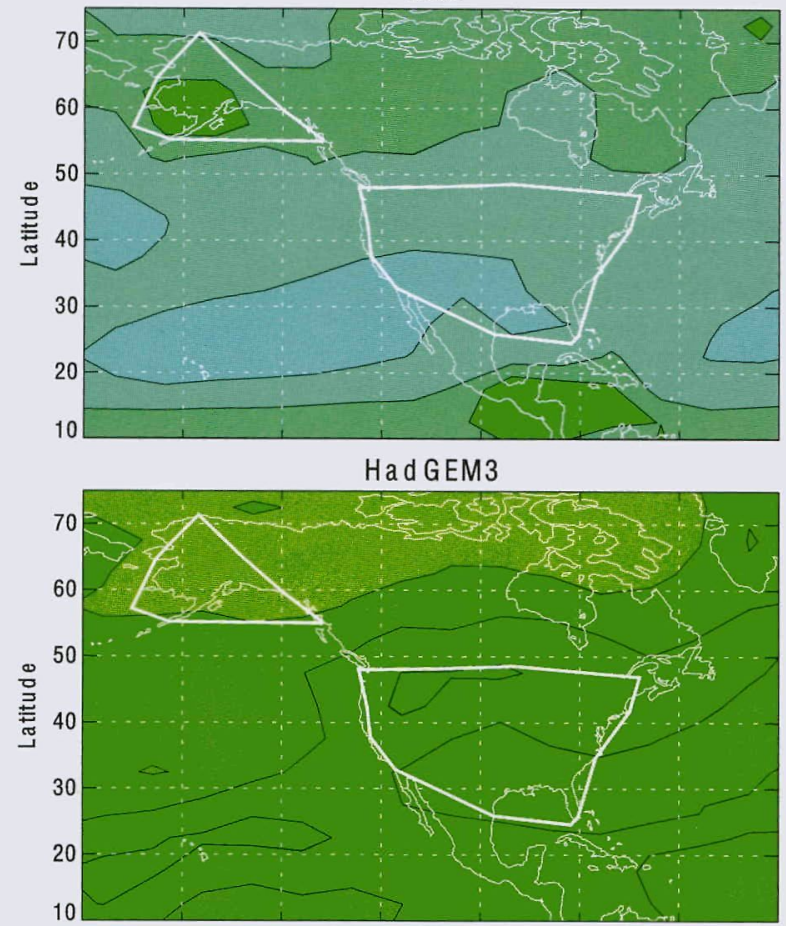

Radiosonde

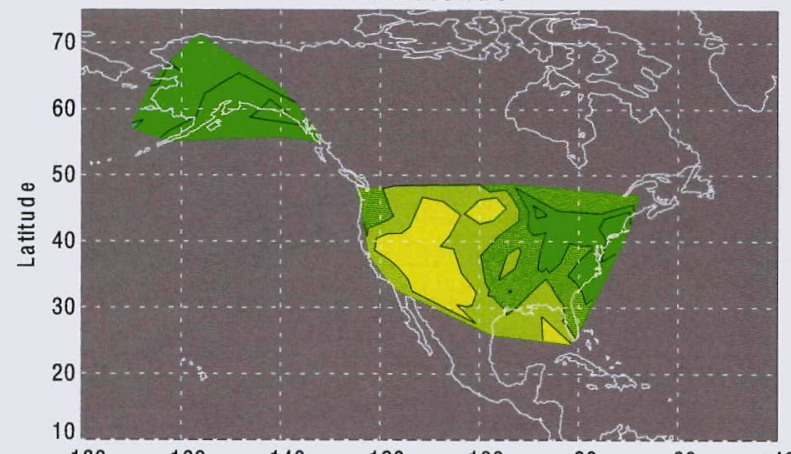

CAM5

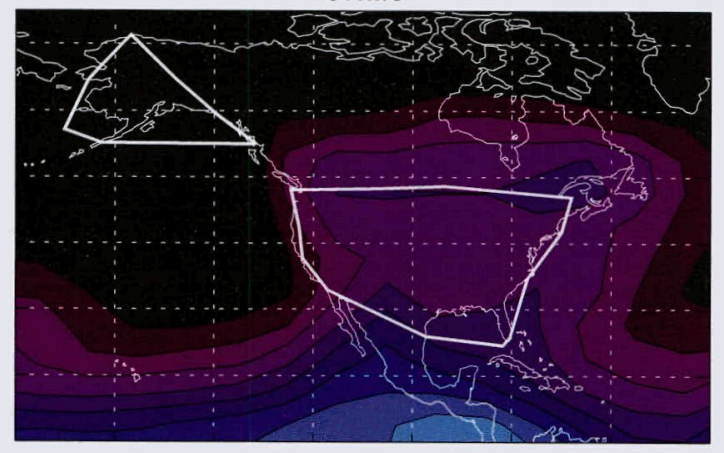

MAECHAM5

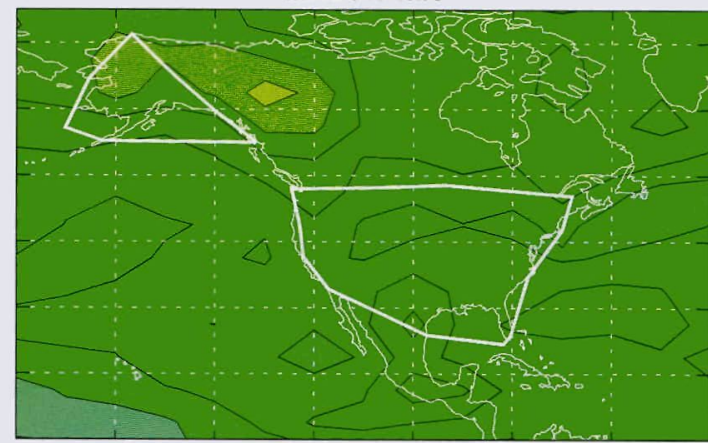

HIRDLS 1

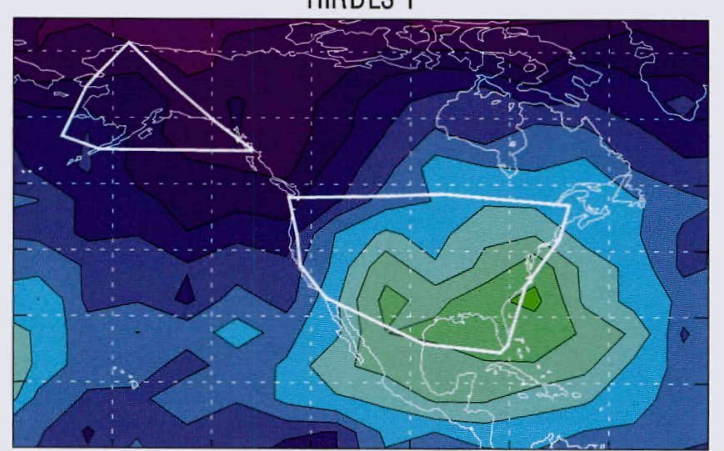

HIRDLS 2

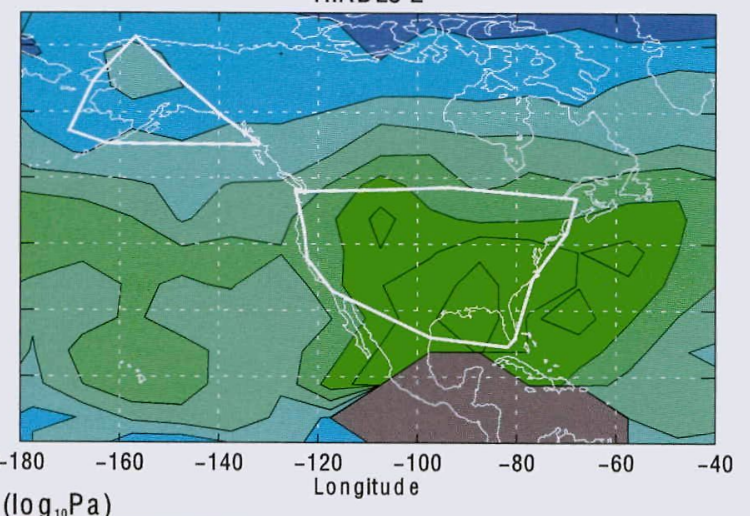

Abs Flux $\left(\log _{10} \mathrm{~Pa}\right)$

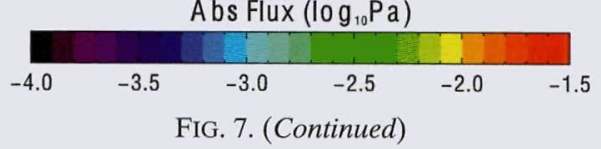




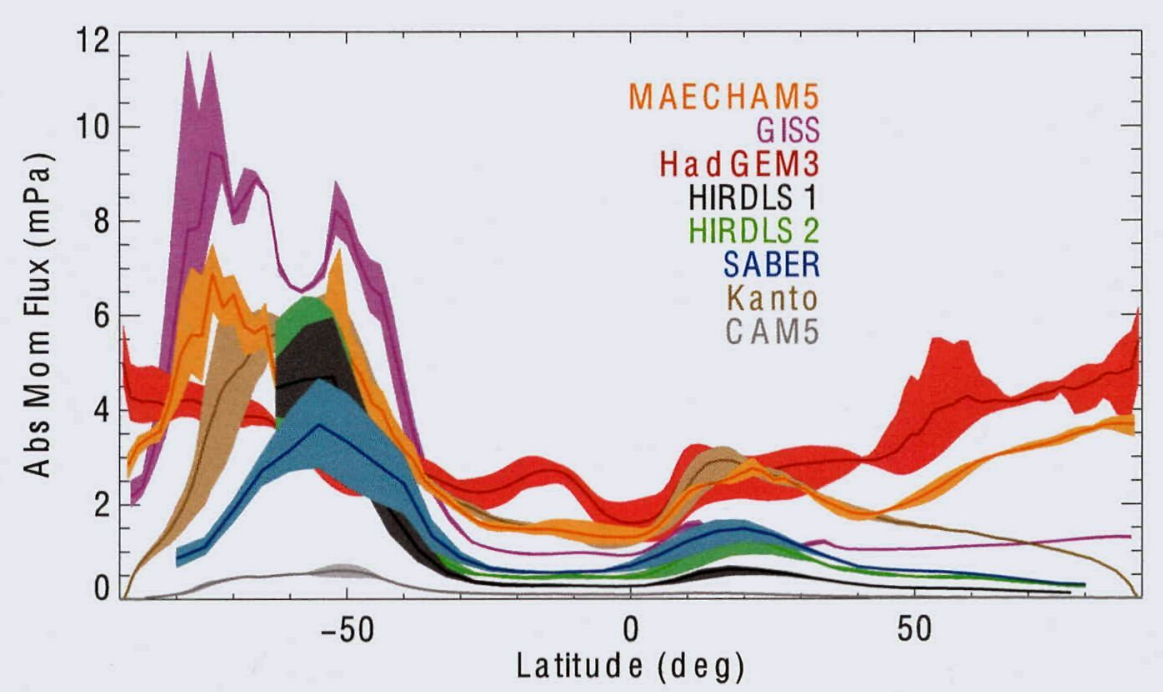

FIG. 8. Interannual variability of the zonal-mean absolute momentum flux for July of 2005 , 2006, and 2007 at $20 \mathrm{~km}$. The color denotes the model or observations and the shaded regions denote the range of variability for these three Julys.

at Fig. 3, for example, we see that, in both January and July, five of the curves fall off faster with increasing altitude than is the case with the three climate models with parameterized gravity wave fluxes, HadGEM3, MAECHAM5, and GISS. These five are the globally averaged fluxes from the satellite-derived fluxes and those from the two high-resolution models, Kanto and CAM5. While the exact reasons for these differences remain unknown, various reasons are likely candidates for these differences.

A likely reason for the more rapid fall off in the satellitederived gravity wave absolute momentum fluxes seen in Fig. 3 is related to limits on the resolved horizontal wavelengths. The shortest possible horizontal wavelength that can be resolved is $\sim 200 \mathrm{~km}$ for HIRDLS and $\sim 400 \mathrm{~km}$ for SABER. In contrast, the climate model parameterizations are seeking to describe waves with shorter horizontal wavelengths, down to tens of kilometers. Longer horizontal wavelength waves tend to break at lower altitudes than shorter horizontal wavelength waves when other parameters are equal (see, e.g., Figs. 3-5 in Alexander and Dunkerton 1999). Thus, perhaps the more rapid fall-off with height seen in the observations should be expected. Another factor that might influence the profiles in Fig. 3 is the process of total internal reflection, which would tend to cause a more rapid falloff with height. However this process is included in one of the parameterizations (GISS), yet one of the others that neglects reflection (HadGEM3) falls off faster, opposite to the expected effect if reflection were important. In addition, reflection is more important for the short horizontal wavelength waves that are not resolved in the observations. So reflection is not likely to explain the differences between the models and observations, but it could play some role. Finally, the practical limit that must be imposed on vertical wavelength in the satellite analyses could induce artificial changes with height if more and more of the flux occurs at vertical wavelengths beyond this limit at increasing altitude. This is an "observational filter" effect (Alexander 1998), and it could also contribute somewhat to the more rapid falloff with height seen in the observations, particularly at the higher altitudes probed by SABER (Preusse et al. 2009a).

The gravity wave parameterizations used in the three climate models in this paper were all different (Hines 1997; Alexander and Dunkerton 1999; Warner and McIntyre 2001), and they all represent simplifications of the actual wave breaking processes. For instance, none deal with secondary wave generation and breaking (e.g., Zhou et al. 2002), and none contain the complexities of gravity wave breaking shown in detailed threedimensional numerical simulations (e.g., Andreassen et al. 1994). The climate models discussed in this paper, however, do produce mean winds and temperatures that are reasonably consistent with observations, so either the resolved wave effects in these models are in error or the gravity wave parameterizations are giving reasonable gravity wave effects in these models. This being said, one should remember that that in each of these models there are separate formulations for the orographic and nonorographic gravity wave effects, and it is likely that there is some nonuniqueness in the combination of these in each of the models. 
Finally, there are various differences in the formulation of the high-resolution models that should be considered. Although, the Kanto model horizontal resolution is more than a factor of 2 coarser than that of CAM5, the Kanto fluxes are larger. The Kanto model has a much higher top (about $85 \mathrm{~km}$ ) than does the CAM5 (around $40 \mathrm{~km}$ ). Furthermore, the Kanto numerical scheme and dissipation were specifically chosen to minimize damping of its finescale features, whereas the CAM5 used here has its numerical scheme and coarse layering designed to produce a sort of "sponge layer" above about $25 \mathrm{~km}$ in which the gravity waves are dissipated to avoid reflections off of its low top. These model differences may very well account for the rapid decrease of explicitly resolved gravity wave fluxes in CAM5 above $25 \mathrm{~km}$ and the Kanto model's gravity wave momentum fluxes being similar to those derived from satellite data at low levels but being much larger at higher levels. It should be stressed here that it is likely that both the Kanto and CAM5 models are underresolving short-wavelength gravity waves that have important associated gravity wave momentum fluxes. A careful study of gravity waves in different high-resolution models needs to be undertaken so that differences between such models are better understood.

The good agreement in the rescaled maps suggests though that the gravity waves seen by the satellite instruments are indicative of the geographical and temporal distribution of the broader spectrum of gravity waves represented in the models. Again, it should be emphasized that this paper represents a first formal comparison between gravity wave fluxes in models and observations, and several issues remain unresolved. Chief among these are why the satellite-observed momentum fluxes fall off so rapidly with height compared to the parameterized wave fluxes and the resolved waves in Kanto.

\section{Some future directions}

There are many encouraging aspects to this first effort at formally comparing gravity wave effects in models with observations. For instance, as mentioned in the introduction, the gravity wave parameterizations in climate models have been developed to be physically reasonable, but the principal constraints on gravity wave parameterizations have been to get winds, temperatures, and transports that are consistent with observations. The parameters in the parameterizations themselves have not been constrained by observations of gravity waves. Nevertheless, many aspects of gravity wave momentum fluxes are seen to be consistent between these models and observations, suggesting that this process has already constrained the parameterizations to some extent. Of course, there are also many aspects where there is disagreement.

The three models with gravity wave parameterizations use very different formulations for nonorographic gravity waves. MAECHAM5 uses the Hines (1997) parameterization and takes their gravity wave source function to be constant globally. HadGEM3 uses the Warner and McIntyre (2001) formulation and also uses a globally uniform gravity wave source function, while the GISS model uses the Alexander and Dunkerton (1999) formulation and uses a climatological gravity wave source function that notionally is meant to represent convective sources in the tropics and jet emission at higher latitudes. These three models use separate orographic gravity wave parameterizations, which are different for each model.

Some of the differences between the model-observations comparisons can be traced to these differences. For instance, comparing Fig. 2 with Fig. 1, one sees that the Kanto and CAM5 models, which explicitly model gravity waves, have momentum fluxes that taper toward zero at the poles like the observations, whereas the models with parameterizations do not. This is likely explained by these three models having nonorographic gravity wave sources that are globally constant, in the case of the MAECHAM5 and HadGEM3 models, or in the case of the GISS model having a constant weak background source function.

Other differences explained by these differences in gravity wave source functions are the greater momentum fluxes at high northern latitudes in July seen in Fig. 5 in the MAECHAM5 and HadGEM3 models relative to the other models and the observations. Clearly, then, more effort is needed in the future using gravity wave observations to improve the specification of model source functions for nonorographic gravity waves.

Some climate models have gravity wave source functions coupled to the model's meteorology. This includes the early work by Rind et al. (1988) and later works by Charron and Manzini (2002) and Richter et al. (2010). While these later works were guided by models for gravity wave generation, improvement of gravity wave source parameterizations should be possible by comparing gravity wave momentum fluxes from observations to those in models for actual atmospheric conditions. An example of where this might help can be seen in Fig. 2 of Richter et al. (2010) and Fig. 7 of Geller et al. (2011), which show that their tropical gravity waves have largest flux over the ITCZ region, whereas Fig. 4 of this paper shows that the largest tropical fluxes are over the summer tropical continent regions.

While this first comprehensive comparison of gravity wave momentum fluxes in observations and models has 
been quite valuable, we stress in section 2 a that further study is needed to better understand how different methods of satellite data analysis affect reported average absolute gravity wave momentum fluxes, especially in view of atmospheric gravity wave intermittency. In the meantime, we recommend that future reporting of satellite-derived gravity wave momentum fluxes include their detailing how their analysis methods affect this averaging, including the fraction of data utilized.

Finally, the satellite-derived gravity wave momentum fluxes were obtained using data from satellite instruments not explicitly designed for gravity wave observations, and this imposed definite limitations. Much better representations of gravity wave momentum fluxes can be obtained from satellite instruments designed explicitly for this purpose.

Acknowledgments. This paper is based on a workshop that was kindly hosted by the International Space Science Institute in Bern, Switzerland, that brought together individuals representing the climate modeling community, including some working with very highresolution global models with those deriving gravity wave momentum fluxes using various means of observations such as using satellite data, using high-verticalresolution radiosonde data, and using free-flying superpressure balloons. The objective of this workshop was to see how the gravity wave momentum fluxes compare among the conventional climate models using gravity wave parameterizations, the high-resolution models, and the momentum fluxes derived from the various observational techniques. Drs. Stephen Eckermann, Takeshi Horinouchi, Robert Vincent, and Corwin Wright were participants in this workshop, and they contributed to the general planning of this paper.

These efforts also were motivated, in part, by the World Climate Research Programme (WCRP) Stratospheric Processes and Their Role in Climate (SPARC) activity on gravity waves. We thank SPARC for their help in supporting this ISSI workshop.

Support for MAG and PTL came from the NASA Earth Science Mission Directorate (Award NNX08AK43G) and the National Science Foundation Climate and Large-scale Dynamics (Award AGS1101258). Support for MJA was from the NASA Earth Science Mission Directorate (Contract NNH11CD32C) and the National Science Foundation Physical and Dynamic Meteorology and Climate and Large-Scale Dynamics programs (Award 0943506). EM was partially funded by the European Commission 7th Framework Programme under GA 226520, COMBINE project. EM is grateful to Pier Giuseppe Fogli for technical assistance. AAS was supported by the Joint DECC/Defra Met Office Hadley Centre Climate Programme (GA01101).

\section{APPENDIX A}

\section{Basics of Gravity Wave Parameterizations in Climate Models}

The physical basis for gravity wave-mean flow interactions is best discussed starting with Eliassen and Palm's (1961) theorem 1 (see also Lindzen 1990),

$$
\overline{p^{\prime} w^{\prime}}=-\left(u_{0}-c\right) \rho_{0} \overline{u^{\prime} w^{\prime}},
$$

where $p$ is atmospheric pressure, $w$ is vertical velocity, $u$ is zonal velocity, $c$ is the gravity wave phase velocity, and $\rho$ is atmospheric density. The subscripts $(\cdot)_{0}$ denote mean state variables, the superscript $(\cdot)^{\prime}$ denotes gravity wave variables, and the overbar $\overline{(\cdot)}$ denotes averaging over gravity wave phase. The expression $\overline{p^{\prime} w^{\prime}}$ is the gravity wave upward energy flux, and $\rho_{0} \overline{u^{\prime} w^{\prime}}$ is the upward flux of gravity wave zonal momentum. Strictly speaking, "wave momentum flux" is a misnomer for the quantity relevant to wave-mean flow interaction, which should strictly be termed "pseudomomentum flux" (Andrews and McIntyre 1978), However, for the approximations that must be made in order to utilize the observational and model results, the distinction is not relevant, so we revert to the simpler term "momentum flux."

Note that Eq. (1) implies that, for $u_{0}>c$ and upward gravity wave energy flux $\overline{p^{\prime} w^{\prime}}>0$, the momentum flux is negative, $\rho_{0} \overline{u^{\prime} w^{\prime}}<0$. This implies that, in the presence of gravity wave dissipation or wave breaking, $\partial\left(\rho_{0} \overline{u^{\prime} w^{\prime}}\right) / \partial z>$ 0 or the divergence of the gravity wave momentum flux is decelerating the mean flow toward c. Note that, if $u_{0}<$ $c$, similar reasoning implies that convergence of the gravity wave momentum flux is accelerating the mean flow toward c. In other words, in the presence of gravity wave dissipation or wave breaking, the action of gravity wave momentum fluxes will be to accelerate or decelerate the flow toward the gravity wave phase velocity $c$.

Climate models typically use separate formulations for orographic and nonorographic gravity waves. Orographically forced gravity waves are forced by the winds interacting with the earth's topography. As computers became more powerful and numerical resolutions increased, it became apparent that there was a westerly bias in tropospheric winds. Palmer et al. (1986) and McFarlane (1987) independently developed parameterizations for including the effects of gravity waves 

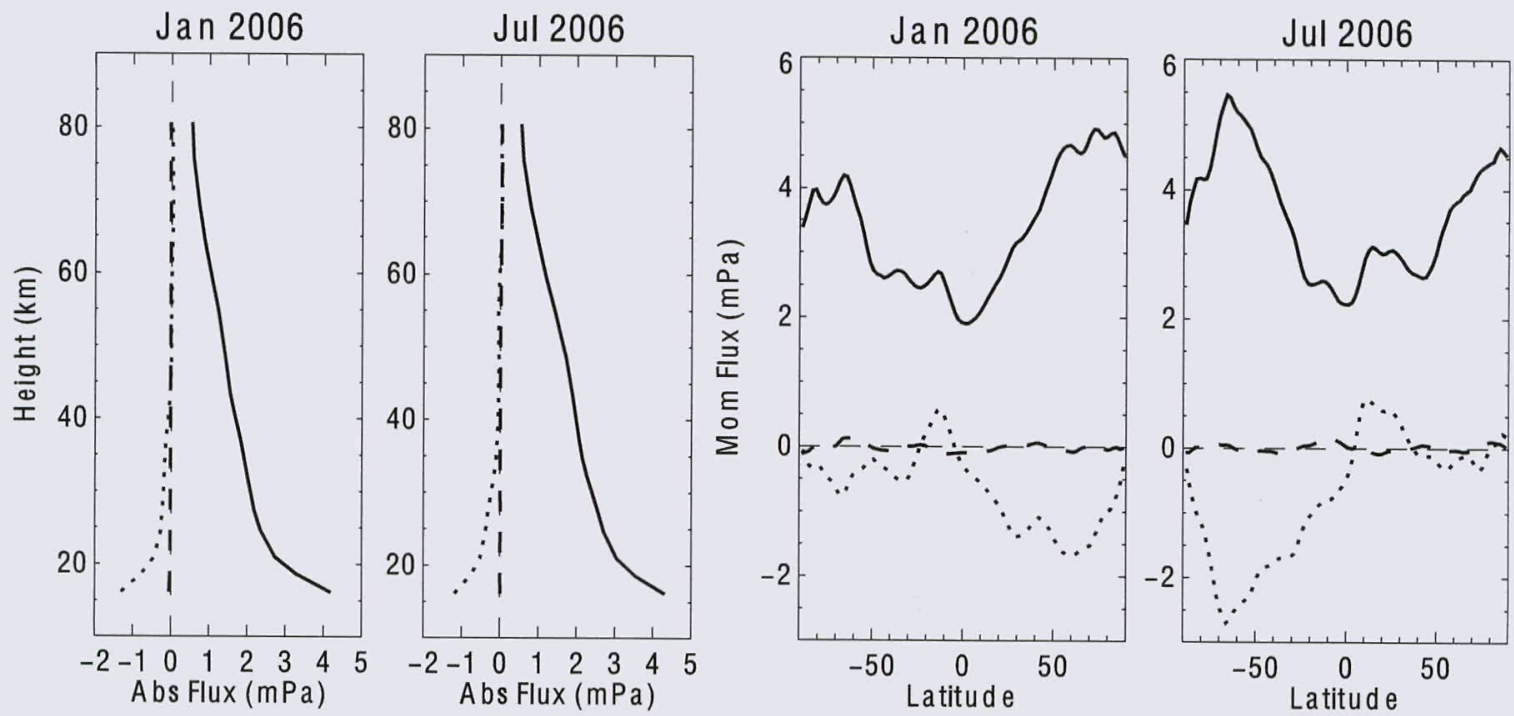

FIG. B1. Comparison between globally averaged absolute and net gravity wave momentum fluxes from the ECHAM model for modeled (left two panels) January and July 2006, respectively, where the solid line is the absolute momentum flux profile, the dotted line is the net east-west momentum flux profile, and the dashed line is the net north-south momentum flux profile. (right two panels) As in (left), but for zonal-mean momentum fluxes at $20 \mathrm{~km}$.

forced by the winds interacting with surface topography at scales that were explicitly resolved at the model resolution. The concept behind orographic gravity wave parameterization can be seen with the aid of Eq. (A1). Since topography is stationary with respect to the rotating earth, orographically forced gravity waves will have phase velocity $c=0$ (although unsteady wind forcing will excite gravity waves with phase velocities having a spread around $c=0$ ). Therefore, orographically forced gravity waves should decelerate the mean zonal winds, where they interact with the mean zonal flow. More sophisticated formulations for parameterizing the effects of orographic gravity waves (e.g., Lott and Miller 1997; Scinocca and McFarlane 2000) have been developed over the years. All state-of-the-art numerical weather prediction and climate models include some form of parameterization for the decelerative effect of unresolved, orographically forced gravity waves.

While the parameterization for orographic gravity waves deals with a clear-cut gravity wave source, the situation is quite different for nonorographic gravity waves. Parameterizing the effects of nonorographic gravity waves tries to deal with gravity waves that originate from a variety of sources. These include moist convection, spontaneous emission from jets and fronts, and instabilities. In many cases, the precise nature of the gravity wave emission from these sources is itself uncertain in a quantitative sense. One thing that all these sources of nonorographic gravity waves have in common though is that they are broad spectrum in the sense of they are emitting waves with a wide variety of frequencies and wavelengths, both horizontal and vertical. While Eq. (A1) indicates that, in wave-mean flow interactions, the wave phase velocity is paramount, the other parameters also play important roles in determining behaviors such as wave reflection, critical layer encounters, and wave breaking. The manner in which these effects are dealt with differ according to the nonorographic gravity wave parameterization, but it is encouraging that McLandress and Scinocca (2005) have found that different parameterizations have very similar influences on the mean flow so long as the wave breaking levels are similar for the different parameterizations.

\section{APPENDIX B}

\section{Absolute versus Net Momentum Fluxes}

While satellite measurements enable the derivation of absolute gravity wave momentum fluxes, it is the net momentum fluxes that are felt in the east-west and north-south equations of motion. Figure B1 shows example comparisons between the net east-west and north-south gravity wave momentum fluxes and the absolute gravity wave momentum fluxes from the MAECHAM5 model. The net north-south fluxes are smaller, reflecting that less wind filtering occurs for the meridionally propagating waves because of the smaller zonally averaged north-south winds. The net momentum fluxes are seen to diminish more quickly with 
increasing altitude than do the absolute fluxes. Also, while the absolute fluxes give some idea of the general magnitude and latitudinal distribution of the fluxes, they show quite a different latitudinal distribution than do the net fluxes.

Thus, while the absolute gravity wave fluxes are not fully representative of the gravity wave momentum fluxes that directly influence the winds through the momentum equation and indirectly affect the temperature structure through the combined effects of their influence in the momentum equations, the continuity equation, and the thermodynamic equation, they do provide a useful quantity for comparison between observations and models.

\section{REFERENCES}

Alexander, M. J., 1998: Interpretations of observed climatological patterns in stratospheric gravity wave variance. J. Geophys. Res., 103 (D08), 8627-8640.

- 2010: Gravity waves in the stratosphere. The Stratosphere: Dynamics, Chemistry, and Transport, Vol. 190, Geophys. Monogr., Amer. Geophys. Union, 43-57.

— mean-flow forcing due to breaking gravity waves. J. Atmos. Sci., 56, 4167-4182.

— , and Coauthors, 2008: Global estimates of gravity wave momentum flux from High Resolution Dynamics Limb Sounder observations. J. Geophys. Res., 113, D15S18, doi:10.1029/ 2007JD008807.

- , and Coauthors, 2010: Recent developments in gravity wave effects in climate models, and the global distribution of gravity wave momentum flux from observations and models. Quart. J. Roy. Meteor. Soc., 136, 1103-1124.

Andreassen, Ø., C. E. Wasberg, D. C. Fritts, and J. R. Isler, 1994: Gravity wave breaking in two and three dimensions 1. Model description and comparison of two-dimensional evolutions. J. Geophys. Res., 99 (D4), 8095-8108.

Andrews, D. G., and M. E. McIntyre, 1978: On wave-action and its relatives. J. Fluid Mech., 89, part 4, 647-664.

Boccara, G., A. Hertzog, R. A. Vincent, and F. Vial, 2008: Estimation of gravity wave momentum flux and phase speeds from quasi-Lagrangian stratospheric balloon flights. Part I: Theory and simulations. J. Atmos. Sci., 65, 3042-3055.

Charron, M., and E. Manzini, 2002: Gravity waves from fronts: Parameterization and middle atmosphere response in a general circulation model. J. Atmos. Sci., 59, 923-941.

Eliassen, A., and E. Palm, 1961: On the transfer of energy in stationary mountain waves. Geofys. Publ., 22, 1-23.

Ern, M., P. Preusse, M. J. Alexander, and C. D. Warner, 2004: Absolute values of gravity wave momentum flux derived from satellite data. J. Geophys. Res., 109, D20103, doi:10.1029/2004JD004752.

— - J. C. Gille, C. L. Hepplewhite, M. G. Mlynczak, J. M. Russell III, and M. Riese, 2011: Implications for atmospheric dynamics derived from global observations of gravity wave momentum flux in stratosphere and mesosphere. J. Geophys. Res., 116, D19107, doi:10.1029/2011JD015821.

Fritts, D. C., and M. J. Alexander, 2003: Gravity wave dynamics and effects in the middle atmosphere. Rev. Geophys., 41,1003, doi:10.1029/2001RG000106.
Geller, M. A., and Coauthors, 2011: New gravity wave treatments for GISS climate models. J. Climate, 24, 3989-4002.

Gille, J., and Coauthors, 2008: High Resolution Dynamics Limb Sounder: Experiment overview, recovery, and validation of initial temperature data. J. Geophys. Res., 113, D16S43, doi:10.1029/2007JD008824.

Giorgetta, M. A., E. Manzini, E. Roeckner, M. Esch, and L. Bengtsson, 2006: Climatology and forcing of the quasibiennial oscillation in the MAECHAM5 model. J. Climate, 19, 3882-3901.

Gong, J., M. A. Geller, and L. Wang, 2008: Source spectra information derived from U.S. high-resolution radiosonde data. J. Geophys. Res., 113, D10106, doi:10.1029/2007JD009252.

Hertzog, A., and F. Vial, 2001: A study of the dynamics of the equatorial lower stratosphere by use of ultra-long-duration balloons 2. Gravity waves. J. Geophys. Res., 106, 22745 22761.

- , G. Boccara, R. A. Vincent, F. Vial, and P. Cocquerez, 2008: Estimation of gravity-wave momentum fluxes and phase speeds from quasi-Lagrangian stratospheric balloon flights. 2: Results from the Vorcore campaign in Antarctica. J. Atmos. Sci., 65, 3056-3070.

Hines, C. O., 1997: Doppler-spread parameterization of gravitywave momentum deposition in the middle atmosphere. Part 2: Broad and quasi monochromatic spectra, and implementation. J. Atmos. Sol. Terr. Phys., 59, 387-400.

Kawatani, Y., K. Sato, T. J. Dunkerton, S. Watanabe, S. Miyahara, and M. Takahashi, 2010: The roles of equatorial trapped waves and internal inertia-gravity waves in driving the quasi-biennial oscillation. Part I: Zonal mean wave forcing. J. Atmos. Sci., 67, 963-980.

Lin, S., 2004: A "vertically Lagrangian" finite-volume dynamical core for global models. Mon. Wea. Rev., 132, 2293-2307.

Lindzen, R. S., 1981: Turbulence and stress owing to gravity wave and tidal breakdown. J. Geophys. Res., 86, 9707-9714.

_ 1990: Dynamics in Atmospheric Physics. Cambridge University Press, $320 \mathrm{pp}$.

Lott, F., and M. J. Miller, 1997: A new subgrid-scale orographic gravity wave parameterization: Its formulation and testing. Quart. J. Roy. Meteor. Soc., 123, 101-127.

Manzini, E., M. A. Giorgetta, M. Esch, L. Kornblueh, and E. Roeckner, 2006: The influence of sea surface temperatures on the northern winter stratosphere: Ensemble simulations with the MAECHAM5 model. J. Climate, 19 , 3863-3881.

McFarlane, N. A., 1987: The effect of orographically excited gravity wave drag on the general circulation of the lower stratosphere and troposphere. J. Atmos. Sci., 44, 17751800.

McLandress, C., and J. F. Scinocca, 2005: The GCM response to current parameterizations of nonorographic gravity wave drag. J. Atmos. Sci., 62, 2394-2413.

Neale, R. B., and Coauthors, 2010: Description of the NCAR Community Atmospheric Model (CAM 4.0). NCAR Tech. Note 485, $212 \mathrm{pp}$.

Palmer, T., G. Shutts, and R. Swinbank, 1986: Alleviation of systematic westerly bias in general circulation and numerical weather prediction models through an orographic gravity wave drag parameterization. Quart. J. Roy. Meteor. Soc., 112 , 2056-2066.

Preusse, P., and Coauthors, 2009a: Global ray tracing simulations of the SABER gravity wave climatology. J. Geophys. Res., 114, D08126, doi:10.1029/2008JD011214. 
— , and Coauthors, 2009b: New perspectives on gravity wave remote sensing by spaceborne infrared limb imaging. Atmos. Meas. Tech., 2, 299-311.

Richter, J. H., F. Sassi, and R. R. Garcia, 2010: Toward a physically based gravity wave source parameterization in a general circulation model. J. Atmos. Sci., 67, 136-156.

Rind, D., R. Suozzo, N. K. Balachandran, A. Lacis, and G. Russell, 1988: The GISS global climate-middle atmosphere model. Part I: Model structure and climatology. J. Atmos. Sci., 45, 329-370.

Russell, J. M., III, M. G. Mlynczak, L. L. Gordley, J. J. Tansock Jr., and R. W. Esplin, 1999: Overview of the SABER Experiment and preliminary calibration Results. Optical Spectroscopic Techniques and Instrumentation for Atmospheric and Space Research III, A. M. Larar, Ed., International Society for Optical Engineering (SPIE Proceedings, Vol. 3756), 277-288.

Sato, K., D. J. O'Sullivan, and T. J. Dunkerton, 1997: Low-frequency inertia-gravity waves in the stratosphere revealed by threeweek continuous observation with the MU radar. Geophys. Res. Lett., 24, 1739-1742.

- S. Watanabe, Y. Kawatani, Y. Tomikawa, K. Miyazaki, and M. Takahashi, 2009: On the origins of mesospheric gravity waves. Geophys. Res. Lett., 36, L19801, doi:10.1029/ 2009GL039908.

Scaife, A. A., N. Butchart, C. D. Warner, D. Stainforth, W. A. Norton, and J. Austin, 2000: Realistic quasi-biennial oscillations in a simulation of the global climate. Geophys. Res. Lett., 27, 3481-3484.

, — - _ , and R. Swinbank, 2002: Impact of a spectral gravity wave parameterization on the stratosphere in the Met Office Unified Model. J. Atmos. Sci., 59, 1473-1489.

Schmidt, G. A., and Coauthors, 2006: Present-day atmospheric simulations using GISS ModelE: Comparison to in situ, satellite, and reanalysis data. J. Climate, 19, 153-192.

Scinocca, J. F., and N. A. McFarlane, 2000: The parameterization of drag induced by stratified flow over anisotropic orography. Quart. J. Roy. Meteor. Soc., 126, 2353-2393.
Shepherd, T. G., 2007: Transport in the middle atmosphere. J. Meteor. Soc. Japan, 85B, 165-191.

Taylor, K. E., R. J. Stouffer, and G. A. Meehl, 2012: An overview of CMIP5 and the experiment design. Bull. Amer. Meteor. Soc., 93, 485-498.

Vincent, R. A., S. J. Allen, and S. D. Eckermann, 1997: Gravitywave parameters in the lower stratosphere. Gravity Wave Processes: Their Parameterization in Global Climate Models, K. Hamilton, Ed., Springer, 7-25.

- A. Hertzog, G. Boccara, and F. Vial, 2007: QuasiLagrangian superpressure balloon measurements of gravitywave momentum fluxes in the polar stratosphere of both hemispheres. Geophys. Res. Lett., 34, L19804, doi:10.1029/ 2007GL031072.

Walters, D. N., and Coauthors, 2011: The Met Office Unified Model Global Atmosphere 3.0 and JULES Global Land 3.0/ 3.1 configurations. Geosci. Model Dev., 4, 919-941.

Wang, L., M. A. Geller, and M. J. Alexander, 2005: Spatial and temporal variations of gravity wave parameters. Part I: Intrinsic frequency, wavelength, and vertical propagation direction. J. Atmos. Sci., 62, 125-142.

Warner, C. D., and M. E. McIntyre, 2001: An ultra-simple spectral parameterization for nonorographic gravity waves. J. Atmos. Sci., 58, 1837-1857.

Watanabe, S., Y. Kawatani, Y. Tomikawa, K. Miyazaki, M. Takahashi, and K. Sato, 2008: General aspects of a T213L256 middle atmosphere general circulation model. J. Geophys. Res., 113, D12110, doi:10.1029/2008JD010026.

Webster, S., A. R. Brown, D. R. Cameron, and C. P. Jones, 2003: Improvements to the representation of orography in the Met Office Unified Model. Quart. J. Roy. Meteor. Soc., 129, 1989 2010, doi:10.1256/qj.02.133.

Zhou, X.-L., J. R. Holton, and G. L. Mullendore, 2002: Forcing of secondary waves by breaking of gravity waves in the mesosphere. J. Geophys. Res., 107, doi:10.1029/ 2001JD001204. 
Copyright of Journal of Climate is the property of American Meteorological Society and its content may not be copied or emailed to multiple sites or posted to a listserv without the copyright holder's express written permission. However, users may print, download, or email articles for individual use. 